\title{
4-Hydroxy-2-pyridone alkaloids: Structures and synthetic approaches
}

\author{
Jessen, Henning Jacob ; Gademann, Karl
}

\begin{abstract}
Hydroxy-2-pyridone alkaloids exert diverse biological effects, ranging from antifungal, antibacterial, insecticidal and cytotoxic activity to the induction of neurite outgrowth in different cell assays. For this reason, this class of compounds has attracted much attention in the scientific community, resulting in the elucidation of the biosynthesis of some members which are formed by fungal polyketide synthases via tetramic acids by fungal polyketide synthases as well as different total synthesis approaches. This article will give a summary of the so far known structures, overview the different activities of the compounds and disclose the synthetic attempts since 1982.
\end{abstract}

DOI: https://doi.org/10.1039/b911516c

Posted at the Zurich Open Repository and Archive, University of Zurich ZORA URL: https://doi.org/10.5167/uzh-210980

Journal Article

Accepted Version

Originally published at:

Jessen, Henning Jacob; Gademann, Karl (2010). 4-Hydroxy-2-pyridone alkaloids: Structures and synthetic approaches. Natural Product Reports, 27(8):1168.

DOI: https://doi.org/10.1039/b911516c 


\title{
4-Hydroxy-2-Pyridone Alkaloids: Structures and Synthetic Approaches
}

\author{
Henning Jacob Jessen, Karl Gademann*,a \\ Author accepted manuscript. Published at DOI: 10.1039/B911516C
}

${ }_{5}$ 4-Hydroxy-2-pyridone alkaloids exert diverse biological effects, ranging from antifungal, antibacterial, insecticidal and cytotoxic activity to the induction of neurite outgrowth in different cell assays. For this reason, this class of compounds has attracted much attention in the scientific community, ${ }_{10}$ resulting in the elucidation of the biosynthesis of some members which are formed by fungal polyketide synthases via tetramic acids by fungal polyketide synthases as well as different total synthesis approaches. This article will give a summary of the so far known structures, overview the different is activities of the compounds and disclose the synthetic attempts since 1982.

\section{Introduction}

4-Hydroxy-2-pyridone alkaloids constitute a family of natural products that are extremely rich in diversity and biological activity. In the last decades, new 20 compounds with intriguing architectures have been unveiled and different synthetic approaches towards these compounds have been developed. Despite the increasing knowledge of the 2-pyridone alkaloid family, many unanswered questions remain concerning their biosynthesis, unknown congeners, biological targets and absolute configuration.

25 The history of the pyridone alkaloids dates back to the $19^{\text {th }}$ century, when Tuson isolated from castor beans a poisonous crystalline substance which he called ricinine (1). ${ }^{1}$ The structural elucidation was accomplished in 1904 by Maquenne and Philippe, ${ }^{2}$ who proposed the 2-pyridone core structure. Many decades later, after the first preliminary data ${ }^{3}$ of two yellow pigments isolated from the insect pathogenic

30 fungi Beauveria bassiana and Beauveria tenella in 1968 had been published, the structural features of the two fungal biochromes tenellin (6) and bassianin (7) were unraveled in 1974 by McInnes et al. ${ }^{4}$ In the meantime, more pyridone alkaloids were isolated, e.g. flavipucine ${ }^{5}$ (29) (1968), funiculosin ${ }^{6}$ (26) (1969), ilicicolin $\mathrm{H}^{7}$ (14) (1971) and the antibiotic kirromycin (45) as a representative of the elfamycins. ${ }^{8}$

35 These findings enriched the chapter of pyridone alkaloids in natural product chemistry that was opened in 1864 and continues until today, as still novel fascinating structures are being discovered. In this review, we will summarize the wealth of information about the different structures, biological effects, biosynthesis and synthetic approaches. This review will focus on 2-pyridones bearing an oxygen 40 atom in the 4-position, while quinoline based structures will not fall within the scope of this article. The elfamycins will only be taken into consideration for the sake of completeness and not in full detail. General approaches to substituted 2-pyridones have been reviewed. ${ }^{9}$ In this article we will focus on the approaches that have been 
applied in the total synthesis of natural products.

\section{Structures, natural sources and known bioactivities}

Due to the diversity of the pyridone natural products, they will be discussed with respect to the linkage in the 3-position, i.e. 3-acyl-, 3-ether- and 3-alkyl-modified 25 pyridones. The following schemes will summarize the known structures. Alhough the elfamycin-type pyridones also contain a 3-acyl modification, these compounds have been grouped separately for reasons of clarity.

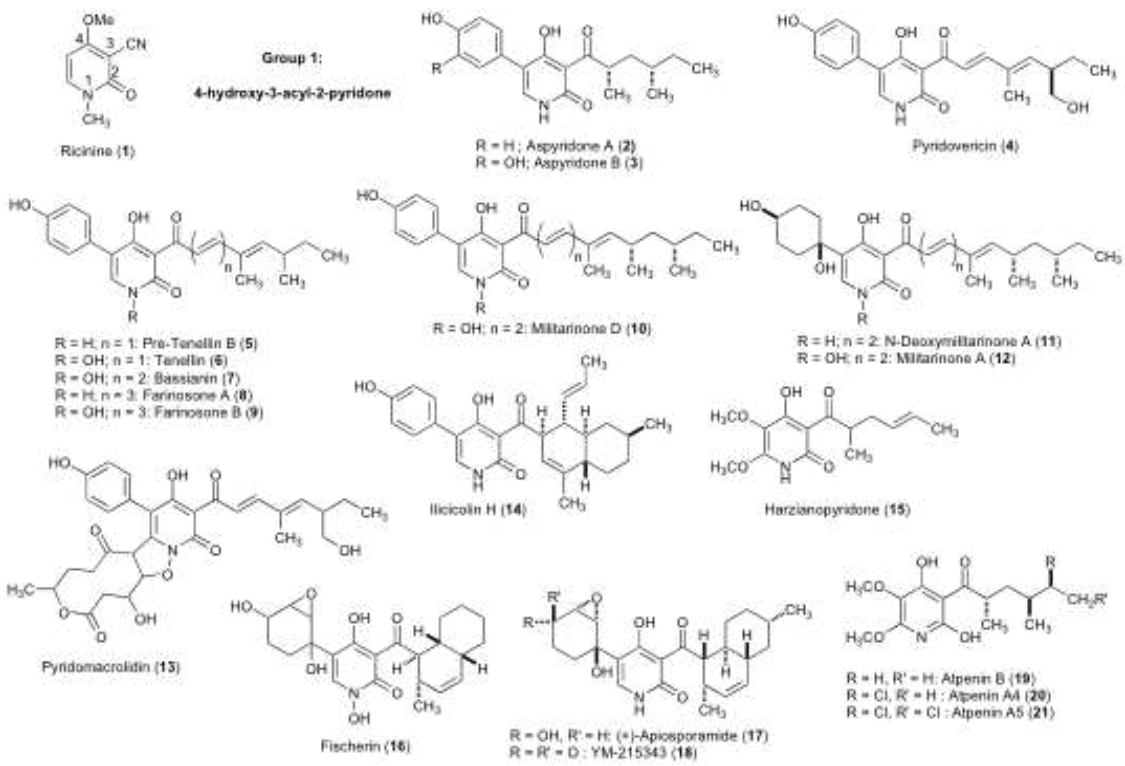

Scheme 1 4-hydroxy-3-acyl-2-pyridones and ricinine (1)

The first group contains all 4-hydroxy-3-acyl modified 2-pyridones and ricinine (1) 10 (Scheme 1). Ricinine (1) is an insecticidal and hepatotoxic alkaloid produced by Ricinus communis which is present in high concentrations in the whole plant (ca. 1 $\mathrm{mg} / \mathrm{g}$ fresh weight). ${ }^{10}$ The cytotoxic aspyridones A (2) and B (3) were discovered in the filamentous fungi Aspergillus nidulans as the product of a silent PKS-NRPS cryptic gene cluster. This gene cluster was activated by ectopic expression under 15 control of an inducible promoter. With this technique the best producer strain generated 2 and 3 from 0.5 to $1 \mathrm{mg} / \mathrm{L}$ of culture broth, enough to determine the relative configuration. ${ }^{11}$ This discovery bears the implication that different pyridone alkaloids may still be found hidden in silenced gene clusters in many other species. Aspyridone B (3) is the only known pyridone alkaloid containing a catechol moiety, 20 whereas the $p$-hydroxyphenyl moiety of $\mathbf{2}$ is found in many other pyridone alkaloids. Pyridovericin (4) is one of the many examples featuring this substitution pattern. Originally isolated from the entomopathogenic fungus Beauveria bassiana in 1998, it was found to inhibit protein tyrosine kinase at high concentrations $(100 \mu \mathrm{g} / \mathrm{mL})$ in crude cell homogenates from $\mathrm{NIH} 3 \mathrm{~T} 3 / \mathrm{v}-\mathrm{src} 1 .{ }^{12}$ Its absolute configuration was ${ }_{25}$ determined by a very interesting quasiracemic synthesis in $2002,{ }^{13}$ that will be presented in more detail later. A group of similar pyridone alkaloids are the yellow biochromes tenellin (6) and its congeners pre-tenellin (5), bassianin (7) and 
farinosone A (8) and B (9). Tenellin (6) was first isolated from the entomopathogenic fungus Beauveria tenella in 1968 and later also found in Beauveria bassiana. ${ }^{14}$ Along with bassianin (7) it was found to be an inhibitor of ATPase in isolated membranes. ${ }^{15}$ Studies to unravel the biosynthesis of tenellin (6) 5 have been performed, which are beyond the scope of this article. ${ }^{16,17}$ Generally, an oxidative ring expansion of tetramic acids to 2-pyridones is discussed. Two racemic syntheses of tenellin (6) have been developed in 1982 and 1989 but the absolute configuration still remains unknown. ${ }^{18,19}$ Pre-tenellin B (5) was isolated after knockout of one of the two open reading frames (ORF) encoding for a cyp450 10 oxidase using RNA silencing techniques. Therefore, pre-tenellin B (5) was found to be the direct precursor of tenellin (6). ${ }^{17}$ More recently, the tetraene 2-pyridones farinosone A (8) and B (9) along with the biosynthetically related farinosone $\mathrm{C}$ have been isolated from the entomopathogenic fungus Paecilomyces farinosus by bioassay guided fractionation. ${ }^{20,21}$ Farinosone A (8) induced neurite outgrowth in the

${ }_{15}$ PC-12 assay, wheras farinosone B (9) was inactive. The absolute configuration of these natural products remains unknown. Other closely related natural products are the militarinones (10-12) isolated from the mycelium of the entomogenous fungus Paecilomyces militaris or Paecilomyces farinosus in the years 2002 to $2006 .^{22-24}$ These natural products induced neurite outgrowth in the PC-12 assay at low 20 concentrations by persistantly activating the PI3-K/PKB and the MEK/ERK pathways. Militarinone A (12) was also capable of inducing apoptosis in the Murine neuroblastoma cell line N2a by nuclear translocation of the apoptosis inducing factor (AIF). ${ }^{25}$ Deoxymilitarinone A (11) was cytotoxic in human neuronal IMR-32 cells at concentrations of $100 \mu \mathrm{M}$. It is intresting to note that $\mathbf{1 1}$ and its hydroxamic acid $\mathbf{1 2}$ 25 isolated from two different strains differed in their signs of optical rotation, although homochirality of the compounds may not generally be assumed. The relative configuration however has been tentatively assigned as syn. Pyridomacrolidin (13) is the only known pyridone alkaloid containing a 10 -membered cyclic lactone. It was isolated in 1998 from Beauveria bassiana along with pyridovericin (4) and found to 30 be a weak inhibitor of protein tyrosine kinase. ${ }^{12}$ The absolute configuration is unknown and there is only one recent study towards a biomimetic synthesis. ${ }^{26}$ The antifungal antibiotic ilicicolin H (14) was isolated in 1971 from the mycelium of the imperfect fungus Cylindrocladium ilicicola. ${ }^{27}$ Its absolute configuration and biosynthesis have been investigated. ${ }^{28,29}$ Additionally, in 1985 a racemic total 35 synthesis using an intramolecular Diels-Alder strategy was presented. ${ }^{30}$ Harzianopyridone (15) has been isolated in 1989 from the fungus Trichoderma harzianum as a racemic mixture and reported to be an antifungal agent. ${ }^{31}$ Later on, a levorotatory sample was also found to be inhibitory towards etiolated wheat coleoptiles (herbicidal) and an inhibitor of the mitochondrial complex II. ${ }^{32,33}$ It is 40 closely related to the atpenins (vide infra). A racemic total synthesis has been published in 1995 leaving the absolute configuration of this molecule undetermined. $^{34}$ Fischerin (16), a complex oxidized hydroxamic acid was first isolated in 1993 from the invasive fungal pathogen Neosartorya fischeri. It was toxic to mice by causing peritonitis. ${ }^{35}$ Only parts of the stereostructure have been 45 solved but it is reminiscent of apiosporamide (17) and YM-215343 (18), structures that have been determined by an elegant total synthesis and proven to be homochiral. ${ }^{36}$ Apiosporamide (17) was isolated from the fungus Apiospora montagnei in 1994, the oxidized congener YM-215343 (18) was found in the fungus Phoma sp. a decade later. ${ }^{37,38}$ Apiosporamide (17) was active against the 
coprophilous fungus Ascobolus furfuraceus and showed antibacterial activity against Bacillus subtilis and Staphylococcus aureus, while YM-215343 (18) showed antifungal activity against the pathogenic fungi Candida albicans, Cryptococcus neoformans, Aspergillus fumigatus (MIC values of 2-16 $\mu \mathrm{g} / \mathrm{ml}$ ) and was cytotoxic 5 against $\mathrm{HeLa}$ S3 cells $\left(\mathrm{IC}_{50}=3.4 \mu \mathrm{g} / \mathrm{mL}\right)$. In 1988, the three antifungal antibiotics atpenin B, A4 and A5 (19-21) were isolated from Penicillium sp. followed by the total structural elucidation in 1990 for atpenin A4 (20) by X-ray crystallography. ${ }^{39,40}$ Like harzianopyridone (15), the atpenins were found to be mitochondrial complex II

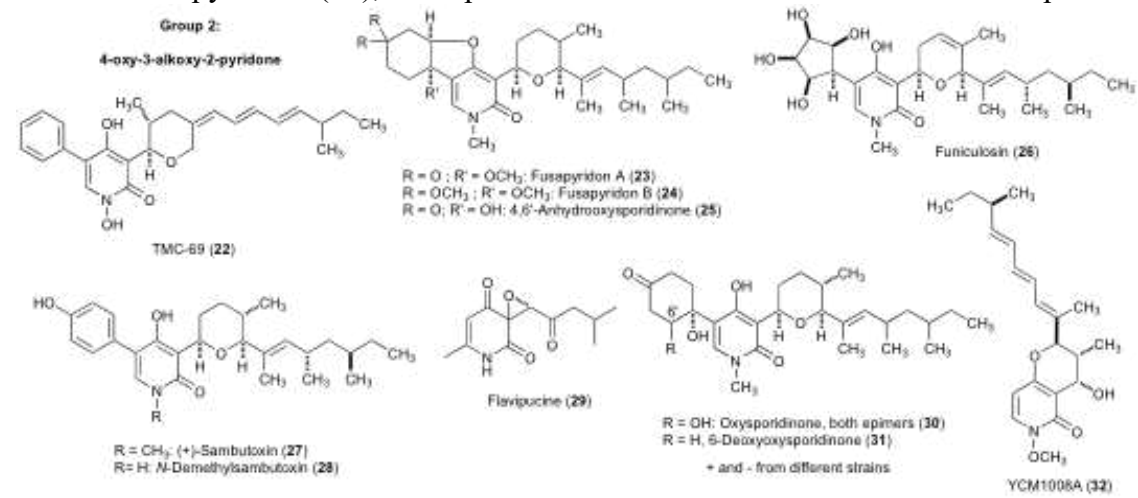

inhibitors. ${ }^{33}$ Atpenin B (19) has been obtained in racemic form from a total synthesis 10 in $1994,{ }^{41}$ whereas atpenin A5 (21) was stereoselectively synthesized in $2009 .{ }^{42}$

Scheme 2 4-oxy-3-alkoxy-2-pyridones

The second group comprises the 4-oxy-3-alkoxy-2-pyridones shown in scheme 2 . TMC-69 (22) is an antitumor antibiotic from Chrysosporium sp. that induced prolongation of the survival time of mice transplanted with B16 melanoma and P388 15 leukemia. The absolute configuration of the THP-moiety could be determined by degradation studies, while the stereogenic center of the side chain remains unassigned. ${ }^{43}$ Because 22 was labile, Kohno et al. transformed it into its stable hexahydrogenated form TMC-69-6H and reported that this molecule was a selective inhibitor of the dual specificity phosphatases Cde25A and B. Fürstner and coworkers 20 presented a stereoselective total synthesis of TMC-69-6H in 2003 but they also were not able to assign the absolute configuration of the side chain stereogenic center. In contrast to the report by Kohno et al., they found a different phosphatase inhibition profile with low inhibition of Cde25A but high inhibition of other phosphatases, e.g. PTP1B and VHR. ${ }^{44}$ Fusapyridon A (23) and its dimethylketal fusapyridon B (24) 25 were isolated in 2007 from Fusarium sp. and $\mathbf{2 3}$ exhibited antimicrobial activity against Pseudomonas aeruginosa and Staphylococcus aureus. ${ }^{45}$ Their structures are resembling 4,6'-anhydro-oxysporidinone (25) from an endophytic strain of Fusarium oxysporum, with fusapyridone A (23) being the methylether of $\mathbf{2 5}$. $^{46}$ The absolute stereostructure and parts of the relative configuration remain to be solved. 30 4,6'-Anhydrooxysporidinone (25) has so far not been found to exert any biological activity in laboratory systems. Funiculosin (26) was discovered as early as 1969 with broad antifungal properties. ${ }^{6}$ Its absolute stereostructure was solved in 1978 by X-ray crystal structure analysis and hydrogenation experiments. ${ }^{47,48}$ It was the first natural product containing a unique all-syn-cyclopentanetetrol moiety. Though ${ }_{35}$ Williams et al. published a stereoselective approach towards funiculosin (26) in 1997, no group has ever managed to finish a total synthesis of this structurally 
intriguing compound. ${ }^{49}$ The mycotoxin sambutoxin (27) was isolated in 1994 from the potato parasite Fusarium sambucinum. It caused toxic effects in rats including weight loss, feed refusal and hemorraghe and was letal to chicken embryos at concentrations of $30 \mu \mathrm{g}$ per egg. ${ }^{50,51}$ Its analog $N$-demethylsambutoxin (28) was 5 discovered in 2006 from extracts of Fusarium oxysporum along with other pyridone alkaloids. ${ }^{52} \mathrm{Up}$ to now, no biological activity has been assigned to $\mathbf{2 8}$. (+)Sambutoxin (27) has been obtained in totally synthetic form and was shown to be the antipode of the naturally ocurring product. ${ }^{53}$ It is interesting to note, that the dimethyl arrays in group 2 are in an anti-fashion, whereas for the militarinones (10-

10 12) a $s y n$-relation has been proposed in the original isolation report. Flavipucin (29), ${ }^{5}$ also known as fruit rot toxin B, contains an interesting spiro-epoxid that has been proposed to be responsible for the activity. It shows antibiotic activity both against gram-positive and gram-negative organisms and phytotoxicity. ${ }^{54} \mathrm{~A}$ cisfusion at the epoxide has been proposed and verified by a racemic total synthesis in 151979 and X-ray diffraction..$^{55,56}$ Oxysporidinone (30) is an oxidized congener of sambutoxin (27), that was discovered in 1997 by Breinholt et al. in Fusarium oxysporum during a screening for natural products inhibiting phytopathogenic fungi such as Aspergillus niger, Botrytis cinerea, Alternaria alternata and Venturia inequalis. Its relative configuration has been solved independently for the ring20 systems. $^{57}$ Both (+)- and (-)-oxysporidinone (30) and the 6-epimer have been isolated from different strains of Fusarium oxysporum. In addition, the 6deoxygenated product (-)-6-deoxyoxysporidinone (31) has been identified. ${ }^{46,52}$ No total synthesis has been reported up to now. The isolation and $\mathrm{Ca}^{2+}$-signalling inhibition properties of YCM1008A (32) from Fusarium sp. in a Saccharomyces ${ }_{25}$ cerevisiae mutant have been reported in $2007 .{ }^{58}$ In the same year, a racemic total

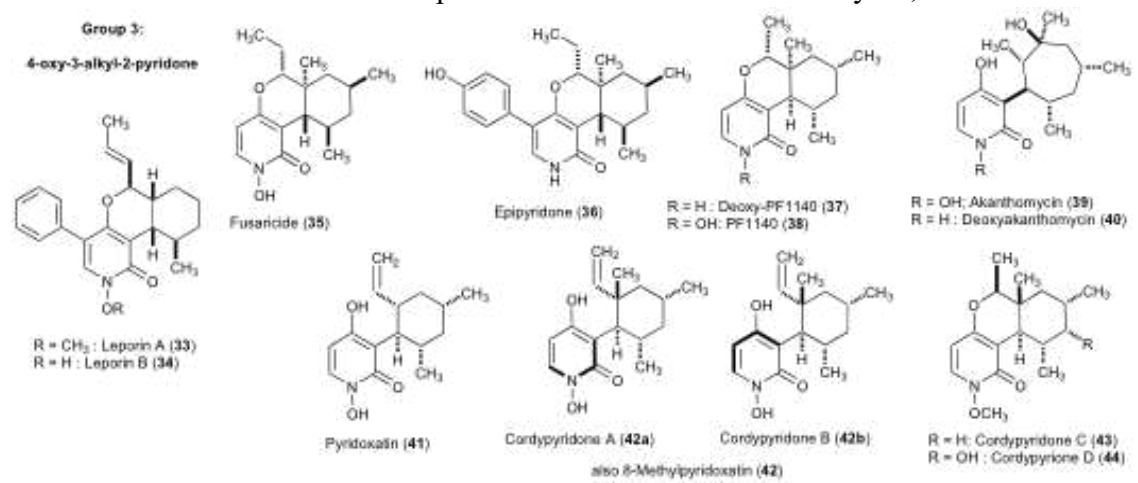

synthesis and the structural determination of the absolute configuration have been published. ${ }^{59}$

Scheme 3 4-oxy-3-alkyl-2-pyridones

The third group contains all 4-oxy-3-alkyl-2-pyridones shown in scheme 3. Tricyclic 30 biaryl leporins A (33) and B (34) have been isolated from Aspergillus leporis in 1991 and 2003, respectively. Leporin A (33) shows activity against the corn earworm Helicoverpa zea and moderate antibacterial activity against Bacillus subtilis. The relative stereostructure of leporin A (33) has been solved and verified in a racemic total synthesis in $1996 . .^{60,61}$ Leporin $\mathrm{B}$ (34) is an inducer of the 35 hexokinase II gene (HKII). It was identified with a rat myoblast cell construct expressing the reporter gene luciferase under control of the HKII promoter. Thus, 
enhancement of HKII transcription enhanced the luciferase signal. ${ }^{62}$ After the isolation of fusaricide (35) in 1996 from Fusarium sp. Snider and coworkers embarked on a total synthesis program that was finished in 2001.63 The relative configuration was solved by X-ray diffraction. It was active in the Rev binding assay 5 rendering it a potential antivirally active substance and also active against Candida albicans and Penicillium chrysogenum (MIC's 16 and $8 \mu \mathrm{g} / \mathrm{ml}$, respectively). Its antitumoral potency was found in vitro but not in vivo against Madison lung carcinoma cell line M109 (1 $\mu \mathrm{g} / \mathrm{ml}) .{ }^{64}$ Epipyridone (36) is the $p$-hydroxyphenyl modified derivative of fusaricide (35). Its natural source is the endofungal 10 filamentous fungus Epicoccum sp. The authors suggest an interesting biosynthetic proposal for the side chain via an intramolecular hetero Diels-Alder reaction, which would also be valid for construction of the structures of e.g. fusaricide (35) and PF1140 (38). No bioactivity has yet been assigned for epipyridone (36) and only the relative configuration is known. ${ }^{65}$ The wide spectrum fungicide PF1140 (38) has

15 been isolated in 1996 and published along with its relative stereostructure. ${ }^{66}$ In 2005 the absolute stereostructure was unraveled by X-ray crystallography of a derivative. ${ }^{67}$ Also in 2005, feeding experiments in Eupenicillium sp., the natural source of PF1140 (38), led the authors to propose a novel biosynthetic pathway to 2pyridones. ${ }^{68}$ Its deoxygenated congener deoxy-PF1140 (37) was found in the culture 20 broth of Penicillium sp. along with PF1140 (38) and deoxyakanthomycin (40). Formation of $\mathbf{4 0}$ was also explained with the newly proposed biosynthetic route. ${ }^{69}$ Interestingly, whereas PF1140 (38) was active in antimicrobial assays against Bacillus subtilis and Candida albicans and modestly active in the murine leukemia bioassay (P388), deoxy-PF1140 (37) lacked activity in these screenings suggesting 25 an important role for the hydroxamic acid. Akanthomycin (39) and its recently discovered congener deoxyakanthomycin (40) (vide supra) exist as atropisomers stemming from hindered rotation around the axis of the pyridone and a stereochemical complex seven-membered ring. Both compounds were discovered in different fungal strains. The producer of Akanthomycin (39) is the 30 entomopathogenic fungus Akanthomyces gracilis, while Penicillium sp. generated (40). The relative structure of (39) was solved by X-ray crystal structure analysis of one of the atropisomers in 2002. Direct application of 39 (both isomers) on agar plates inhibited the growth of Staphylococcus aureus at $250 \mathrm{ng} .^{70} \mathrm{In}$ a screening assay for radical scavengers of microbial origin in 1991, the fungus Acremonium sp. 35 was found to produce a rotameric mixture of pyridoxatin (41), that was about 20 times as active as vitamin $\mathrm{E}$ (inhibition of lipid peroxidation in rat liver microsomes). ${ }^{71}$ This activity was proposed to originate from tight iron chelation of the hydroxamic acid. Interestingly, a (pyridoxatin) ${ }_{3} \mathrm{Fe}$ - complex has been isolated from another source and the absolute configuration determined by X-ray diffraction 40 and CD-spectroscopy (antipode of that shown for 41) ${ }^{72}$ A racemic total synthesis was presented in 1994 by Snider and $\mathrm{Lu}^{73}$ The first report on 8-methylpyridoxatin (42) dates back to 1999, when it was discovered in a screening for EPO-inducing compounds based on a luciferase reporter technology in the fungal strain OSF61800. ${ }^{74}$ Confusingly, it was later found in another entomopathogenic fungal strain ${ }_{45}$ Cordyceps nipponica and both atropisomers renamed to cordypyridone A (42a) and $\mathrm{B}(\mathbf{4 2 b}){ }^{75}$ In this isolation procedure, potent antimalarial activity against Plasmodium falciparum was reported $\left(\mathrm{IC}_{50}=0.066\right.$ and $\left.0.037 \mu \mathrm{g} / \mathrm{mL}\right)$ in addition to the unveiling of the absolute stereostrucure. In 2009 a racemic synthesis of cordypyridones A (42a) and B (42b) with separation of the atropisomers was 
reported. ${ }^{76}$ In the same publication presenting the structures of $\mathbf{4 2 a}$ and $\mathbf{4 2 b}$ also the relative stereostructures of cordypyridones $C(\mathbf{4 3})$ and $D(\mathbf{4 4})$ were disclosed. ${ }^{75}$ Both compounds showed no antimalarial activity against Plasmodium falciparum.

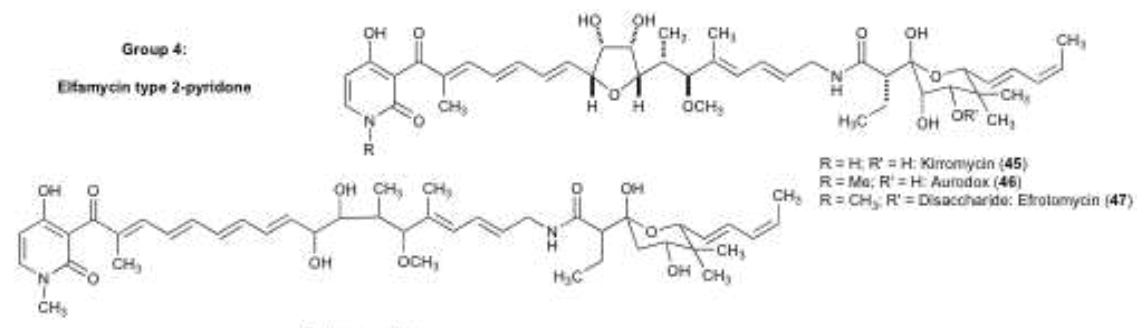

Facturgan (43)

Scheme 4 Elfamycin type 2-pyridones

Only a few examples of the elfamycin type 2-pyridones are shown in scheme 4 . The most famous of these antibiotics are kirromycin (45), aurodox (46), efrotomycin (47) and factumycin (48). The elfamycins inhibit the bacterial elongation factor EF-Tu. ${ }^{77}$ Both aurodox (46) and efrotomycin (47) have been prepared by a stereoselective 10 total synthesis in 1985 by Nicolaou and Dolle. ${ }^{78,79}$ A detailed discussion of these compounds is beyond the scope of this article. Further information can be found in a recent article by Wohlleben et al. and the references cited therein. ${ }^{80}$

Table 1 Overview of pyridone alkaloids, their primary biological source and year of isolation

\begin{tabular}{|c|c|c|c|}
\hline Natural Product & Source & Isolation & Total synthesis \\
\hline Ricinine (1) & Ricinus communis & 1864 & 1923 \\
\hline Aspyridone A (2) & Aspergillus nidulans & 2007 & \\
\hline Aspyridone B (3) & Aspergillus nidulans & 2007 & \\
\hline Pyridovericin (4) & Beauveria bassiana & 1998 & Quasiracemic in 2002 \\
\hline Pre-Tenellin B (5) & Beauveria bassiana & 2008 & \\
\hline Tenellin (6) & Beauveria tenella & 1968 & Racemic in 1982 / 1989 \\
\hline Bassianin (7) & Beauveria bassiana & 1968 & \\
\hline Farinosone A (8) & Paecilomyces farinosus & 2004 & \\
\hline Farinosone B (9) & Paecilomyces farinosus & 2004 & \\
\hline Militarinone D (10) & Paecilomyces militaris & 2003 & \\
\hline$N$-Deoxymilitarinone A (11) & Paecilomyces farinosus & 2006 & \\
\hline Militarinone A (12) & Paecilomyces militaris & 2002 & \\
\hline Pyridomacrolidin (13) & Beauveria bassiana & 1998 & \\
\hline Ilicicolin H (14) & Cylindrocladium ilicicola & 1971 & Racemic in 1985 \\
\hline Harzianopyridone (15) & Trichoderma harzianum & 1989 & Racemic in 1995 \\
\hline Fischerin (16) & Neosartorya fischeri & 1993 & \\
\hline Apiosporamide (17) & Apiospora montagnei & 1994 & Stereoselective in 2005 \\
\hline YM-215343 (18) & Phoma sp. & 2004 & Stereoselective in 2005 \\
\hline
\end{tabular}




\begin{tabular}{|c|c|c|c|}
\hline Atpenin B (19) & Penicillium $s p$. & 1988 & Racemic in 1994 \\
\hline Atpenin A4 (20) & Penicillium sp. & 1988 & \\
\hline Atpenin A5 (21) & Penicillium sp. & 1988 & Stereoselective in 2009 \\
\hline TMC-69 (22) & Chrysosporium sp. & 2001 & \\
\hline Fusapyridon A (23) & Fusarium $s p$. & 2007 & \\
\hline Fusapyridon B (24) & Fusarium sp. & 2007 & \\
\hline Anhydrooxysporidinone (25) & Fusarium oxysporum & 2007 & \\
\hline Funiculosin (26) & Penicillium funiculosum & 1969 & \\
\hline$(+)$-Sambutoxin $(27)$ & Fusarium sambucinum & 1994 & Stereoselective in 2000 \\
\hline$N$-Demethylsambutoxin (28) & Fusarium oxysporum & 2006 & \\
\hline Flavipucine (29) & Aspergillus flavipes & 1968 & Racemic in 1979 \\
\hline Oxysporidinone (30) & Fusarium oxysporum & 1997 & \\
\hline 6-Deoxysporidinone (31) & Fusarium oxysporum & 2007 & \\
\hline YCM1008A (32) & Fusarium sp. & 2007 & Racemic in 2007 \\
\hline Leporin A (33) & Aspergillus leporis & 1991 & Racemic in 1996 \\
\hline Leporin B (34) & Aspergillus leporis & 2003 & \\
\hline Fusaricide (35) & Fusarium sp. & 1996 & Racemic in 2001 \\
\hline Epipyridone (36) & Epicoccum sp. & 2007 & \\
\hline Deoxy-PF1140 (37) & Penicillium sp. & 2009 & \\
\hline PF1140 (38) & Eupenicillium sp. & 1996 & \\
\hline Akanthomycin (39) & Akanthomyces gracilis & 2002 & \\
\hline Deoxyakanthomycin (40) & Penicillium sp. & 2009 & \\
\hline Pyridoxatin (41) & Acremonium sp. & 1991 & Racemic in 1994 \\
\hline 8-Methylpyridoxatin (42) & fungus OS-F61800 & 1999 & Racemic in 2009 \\
\hline Cordypyridone C (43) & Cordyceps nipponica & 2001 & \\
\hline Cordypyridone D (44) & Cordyceps nipponica & 2001 & \\
\hline Kirromycin (45) & Streptomyces collinus & 1972 & \\
\hline Aurodox (46) & Streptomyces goldiniensis & 1973 & Stereoselective in 1985 \\
\hline Efrotomycin (47) & Nocardia lactamdurans & 1976 & Stereoselective in 1985 \\
\hline Factumycin (48) & Streptomyces lavendulae & 1982 & \\
\hline
\end{tabular}




\section{Synthetic approaches towards pyridone alkaloids}

Regarding the strategic construction of the natural products outlined above, there are basically two general approches towards the pyridone alkaloids, i.e. the modification of a preformed pyridone core structure with (often) electrophilic reagents or a linear route with a late stage cyclization event. Both strategies will be discussed in detail in the following chapter.

\subsection{Cyclization strategies for pyridone alkaloids}

One of the first synthetic strategies for the construction of pyridone alkaloids dates 10 back to $1982^{18}$ and was developed by David Williams and coworkers, who later disclosed other innovative strategies for the synthesis of these compounds.

\subsubsection{Racemic total syntheses of tenellin (6) and ilicicolin H (14) by Dieckmann condensation}

15 Preparation of tenellin (6) commenced with the condensation of methylester 49 and $N, N$-DMF dimethyl acetal (scheme 5). Subsequent exchange with benzyloxyamine gave the vinylogous carbamate $\mathbf{5 0}$ exclusively as the $E$-isomer. As a cyclization would only proceed via the $Z$-isomer thus requiring olefin geometry inversion, reduction with sodium cyanoborohydride followed by acylation with diketene 20 afforded $\beta$-keto hydroxamic acid 51. Cyclization ocurred after saponification and imidazolyl activation followed by internal acylation after deprotonation with sodium hydride yielding heterocyle $\mathbf{5 2}$.

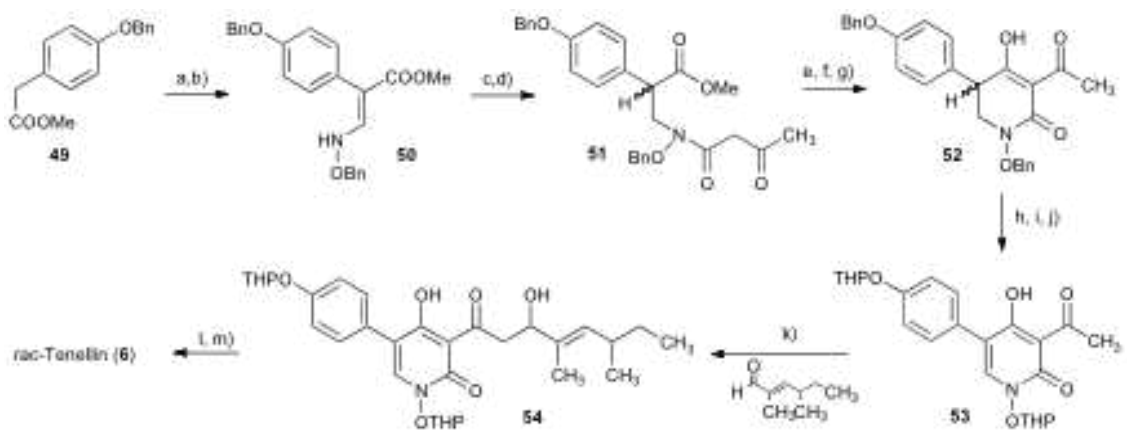

Scheme 5 Total synthesis of tenellin (6). Conditions: a) $N, N$-Dimethylformamide dimethylacetal, $200{ }^{\circ} \mathrm{C}, 12 \mathrm{~h}, 87 \%$; b) (Benzyloxy)amine, benzene, CSA, $80{ }^{\circ} \mathrm{C}$, quant.; ethanolic $\mathrm{HCl}, \mathrm{NaCNBH}_{3}$, $254.5 \mathrm{~h}, 96 \%$; d) diketene, THF, $\mathrm{Et}_{3} \mathrm{~N},-78{ }^{\circ} \mathrm{C}$, quant.; e) $\mathrm{LiOH}, \mathrm{THF} / \mathrm{H}_{2} \mathrm{O}, 99 \%$; f) $1,1-$ carbonyldiimidazole, THF, $0{ }^{\circ} \mathrm{C}$ then $\mathrm{g}$ ) $\mathrm{NaH}, 91 \%$; h) Chloranil, ethylbenzene, reflux, 85\%; i) $\mathrm{H}_{2} / \mathrm{Pd} / \mathrm{C}$, dioxane, then j) dihydropyran, THF, CSA, $0{ }^{\circ} \mathrm{C}, 94 \%$; $\mathrm{k}$ ) LDA, THF, $-78{ }^{\circ} \mathrm{C}, 56 \%$; 1 ) $\mathrm{Et}_{3} \mathrm{~N}$, $\mathrm{CSA}, \mathrm{CHCl}_{3}$, reflux, then $\mathrm{m}$ ) $\mathrm{CSA}, \mathrm{MeOH}$, benzene, reflux, $82 \%$.

After oxidation with chloranil, the benzyl ether protecting groups had to be 30 exchanged to THP protecting groups. Protected pyridone $\mathbf{5 3}$ was used in an aldol reaction with excess aldehyde giving a complex diastereomeric mixture of alcohol 54. E-selective elimination in anhydrous chloroform/triethylamine $4: 1$ and deprotection with camphorsulfonic acid gave rac-tenellin (6) in a good overall yield. ${ }^{18}$ 
Only three years later, Williams and coworkers published the racemic total synthesis of ilicicolin H (14) starting from the known intermediate 52 (scheme 5) after oxidation with chloranil (compound 55). ${ }^{30}$ This time, aldol reaction with $\mathrm{KO} t \mathrm{Bu}$ and fourfold excess of the racemic aldehyde 56, which was obtained from citronellol 5 acetate in eleven steps, gave the addition product that directly eliminated to bisdiene 57. Interestingly, though this compound had several ways to react under DielsAlder conditions (heating in dichlorobenzene for five minutes, $80 \%$ yield), a facile cycloaddition was observed proceeding through the exo-bridged transition state giving trans-fused decalins $\mathbf{5 8}$ and $\mathbf{5 9}$ with the remote C-12 methyl substituent in an 10 equatorial position. The main product $\mathbf{5 8}$ and the isomerized conjugated byproduct 59 (5:1 mixture) were utilized as a mixture for the completion of the reaction sequence. First, treatment with excess LDA at $-78{ }^{\circ} \mathrm{C}$ deprotonated the benzylic position of the hydroxamic acid benzyl ether leading to loss of benzaldehyde and net reduction at $N-1$. Hydrolysis of the reaction produced the desired configuration at C15 8. Cleavage of the remaining benzyl ether with boron trichloride then furnished racemic ilicicolin $\mathrm{H}$ (14). The yield for the penultimate conversion c) is not reported in the publication.

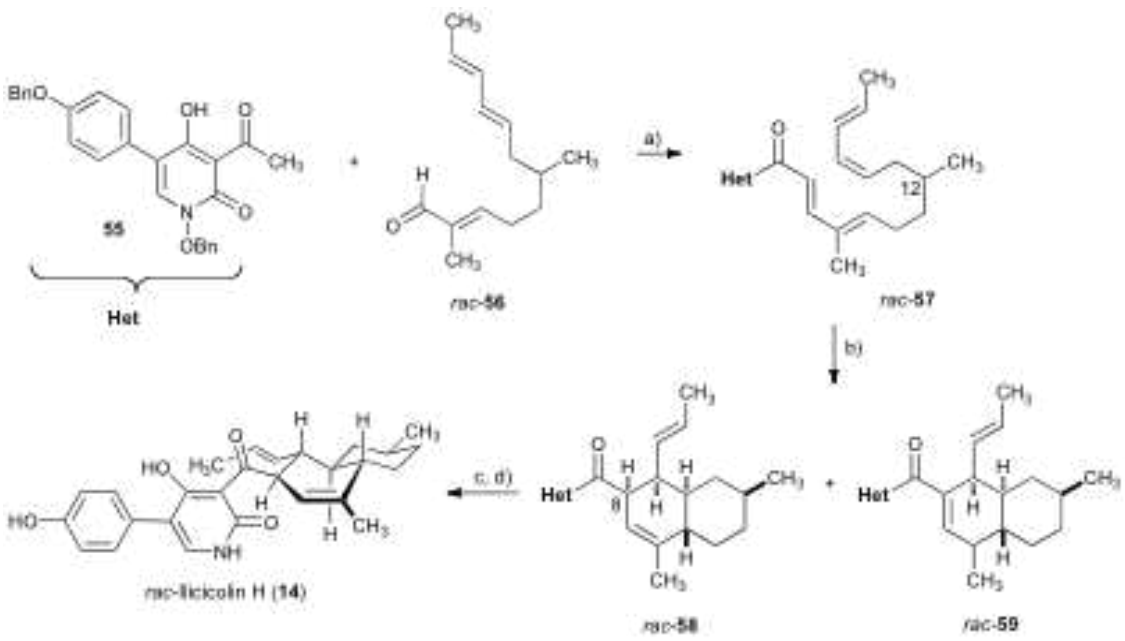

Scheme 6 Total synthesis of ilicicolin $\mathrm{H}$ (14). Conditions: a) 4 eq. 56, 4 eq. $\mathrm{KO} t \mathrm{Bu},-40{ }^{\circ} \mathrm{C}$, THF, $204 \mathrm{~h}, 72 \%$; b) $o$-dichlorobenzene, reflux, $5 \mathrm{~min}, 80 \% \mathbf{5 8}+\mathbf{5 9}(5: 1)$; c) excess LDA, THF, $-78{ }^{\circ} \mathrm{C}, 20$ min, then $\mathrm{HOAc} / \mathrm{H}_{2} \mathrm{O}$; d) $\mathrm{BCl}_{3}$, DCM, $-78{ }^{\circ} \mathrm{C}, 1 \mathrm{~min}$, then $\mathrm{MeOH}, 60 \%$. 


\subsubsection{Racemic total syntheses of tenellin (6) via cyclocondensation of an isocyanate with a $\beta$-keto ester enolate}

Another convergent synthesis of rac-tenellin was reported by Rigby and Qabar. ${ }^{19}$ The reaction began with the preparation of a cinnamate derived isocyanate $\mathbf{6 1}$ 5 starting from aldehyde 60, that was protected, elongated with a Horner-WadsworthEmmons reaction followed by hydrolysis of the ester. The resulting carboxylic acid was then transformed into the isocyanate either by generating an intermediate acylazide with diphenyl phosphorazidate ${ }^{81}$ followed by several hours of refluxing or by using the Weinstock ${ }^{82}$ mixed anhydride protocol.

10

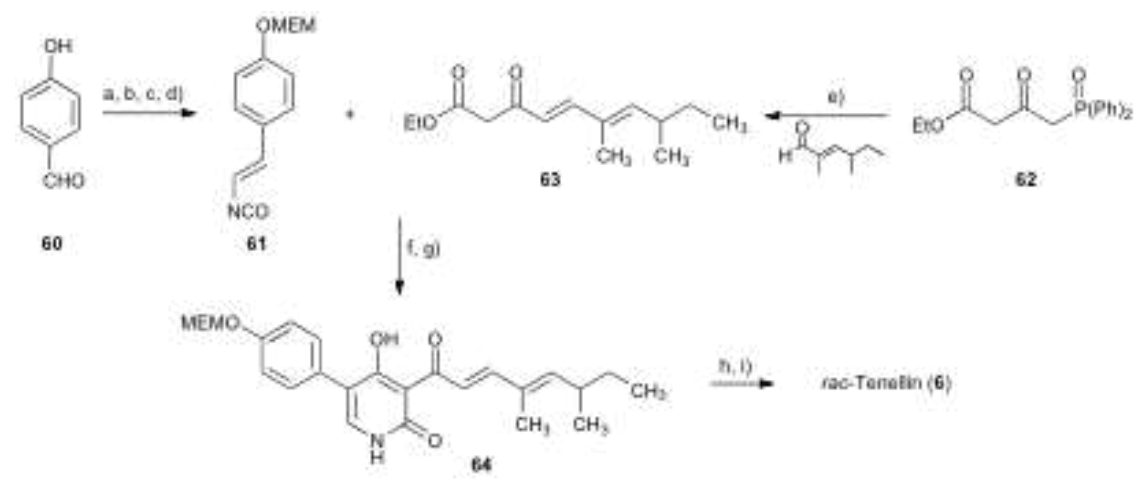

Scheme 7 Total synthesis of tenellin (6). Conditions: a) MEMCl, DIPEA, rt; b) $\left.(\mathrm{EtO})_{2} \mathrm{POCH}_{2} \mathrm{CO}_{2} \mathrm{Et}, \mathrm{NaH}, \mathrm{THF} ; \mathrm{c}\right) \mathrm{LiOH} / \mathrm{H}_{2} \mathrm{O}$, rt, (95\% over three steps); d) EtOCOCl, $\mathrm{Et}_{3} \mathrm{~N}$, $\mathrm{NaN}_{3}$, toluene, reflux, $90 \%$; e) $\mathrm{NaH}$, THF, $0{ }^{\circ} \mathrm{C}$, then $n \mathrm{BuLi}, 0{ }^{\circ} \mathrm{C}$, then aldehyde, $75 \%$; f) $\mathrm{NaH}$, THF, then g) 61, $\mathrm{Ph}_{2} \mathrm{O}, 250{ }^{\circ} \mathrm{C}, 3 \mathrm{~min}, 70 \%$; h) TMS-Cl, NaI, MeCN, $85 \%$; i) $\mathrm{TMS}_{2} \mathrm{NH}$, cat. 15 TMSCl, reflux, then $\mathrm{MoO}_{5} *$ py*HMPA, DCM, rt, $42 \%$.

The sodium salt of $\beta$-keto ester $\mathbf{6 3}$, obtained from the dianion of phosphonate $\mathbf{6 2}$ in a HWE-reaction, reacts smoothly via an enolate addition with the isocyanate $\mathbf{6 1}$, giving an intermediate enamide that is immediately cyclized at $250{ }^{\circ} \mathrm{C}$ in diphenylether. MEM cleavage followed by oxidation of TMS-protected pyridine 20 with Vedejs reagent ${ }^{83}$ furnished $r a c$-tenellin (6) in $42 \%$ yield. Despite the interesting construction of the pyridone structure, this method surely suffers from the harsh conditions that have to be applied to initiate the cyclization reaction. On the other hand it provided quick access to racemic tenellin (6) in good overall yield.

\section{${ }_{25}$ 2.1.3 Quasiracemic total syntheses of pyridovericin via the isocyanate approach}

Quasiracemic synthesis tries to combine the advantages of racemic and stereoselective synthesis, i.e. making both enantiomers at the same time but starting and finishing with enantiopure material. ${ }^{84}$ This is achieved by tagging both enantiomers with different but very similar protecting groups, mixing them to a 30 quasiracemate, conducting the synthesis on both quasienantiomers and finally by demixing taking advantage of the tag. After removal of the tag, both quasienantiomers are converted to pure enantiomers. Ideally, both quasienantiomers should have very similar, preferably identical physical properties but there should be at least one orthogonal method for resolution of the tags. The use of this concept has 35 been demonstrated in the quasiracemic total synthesis of pyridovericin (4) in 2002 
using a fluorous tagging strategy. ${ }^{13}$ In this synthesis different perfluorinated protecting groups as the tags were attached to a $\beta$-keto ester-fragment that was used in a cyclocondensation as described in 2.1.2.

Scheme 8 Quasiracemic total synthesis of pyridovericin (4). Conditions: a) (COCl $)_{2}$, DMSO, then b)

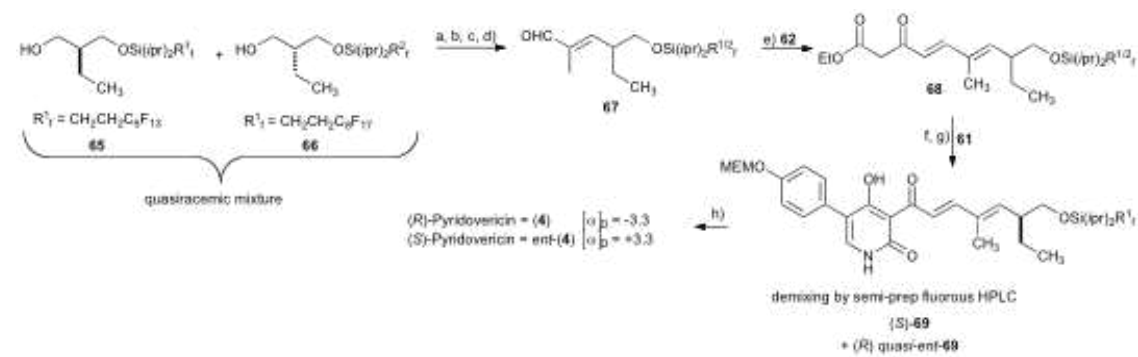

${ }_{5} \mathrm{Ph}_{3} \mathrm{PC}\left(\mathrm{CH}_{3}\right) \mathrm{CO}_{2} \mathrm{Et}, 80 \%$ (2 steps); c) DIBAL, d) see a), $72 \%$; e) LDA, 78 \%; f) NaH; g) $\mathrm{Ph}_{2} \mathrm{O}, 250$ ${ }^{\circ} \mathrm{C}, 32 \%$ (two steps); h) TMS-Cl, NaI, MeCN, $90 \%$.

The differently tagged quasi-enantiomers $\mathbf{6 5}$ and $\mathbf{6 6}$ were mixed resulting in a quasiracemic mixture that was converted to the aldehyde $\mathbf{6 7}$ via Swern oxidation, Wittig reaction, DIBAL reduction followed by another Swern oxidation. At this 10 stage the authors stated that they detected racemization (only after completion of the synthesis) of the quasiracemate from enantiopure material to a purity of about $64 \%$ $e e$. They showed that both Wittig reaction and reduction caused this decrease in optical purity. Preparation of the $\beta$-keto ester $\mathbf{6 8}$ followed by enolate addition/cyclization as in 2.1.2. gave the quasiracemate of $\mathbf{6 9}$, that was now 15 separated by using fluorous HPLC, thus resolving the quasiracemate. Deprotection gave $(R)$ and $(S)$-pyridovericin (4), in low enantiomeric excess due to the racemization of the quasiracemic mixture in the reaction sequence. However, because no complete racemization had taken place, comparison of the optical rotation allowed to assign the absolute configuration of natural pyridovericin (4) 20 being $(R)$. In the original publication, the authors also showcased the use of this technique on a compound, which is not prone to racemization. ${ }^{13}$ In this case, better results were obtained. 


\subsubsection{Construction of (+)-sambutoxin with an enol-ester approach}

In 2000 Williams and Turske presented a novel approach towards the construction of densely functionalized pyridone core structures. ${ }^{53}$ This was exemplified in the enantioselective total synthesis of (+)-sambutoxin (27), the antipode of the natural 5 product.

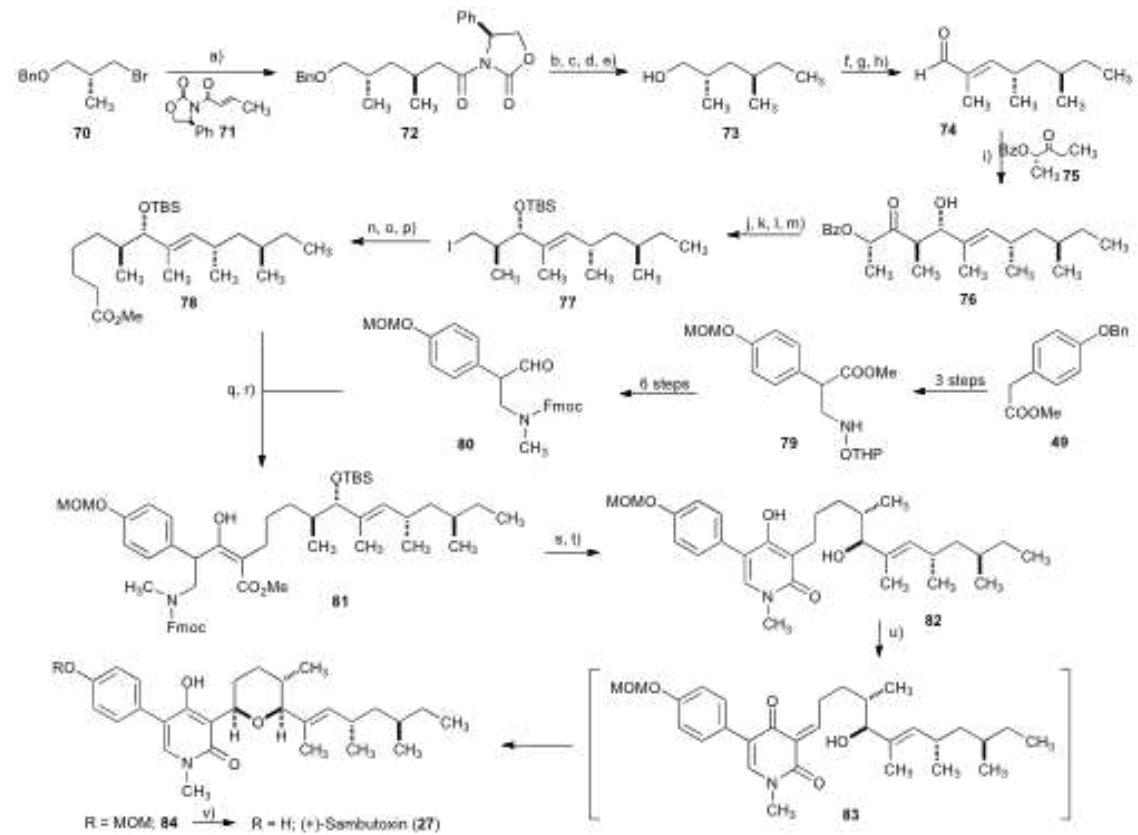

Scheme 9 Enantioselective total synthesis of sambutoxin (27). Conditions: a) Mg, CuBr*DMS, THF, $-78{ }^{\circ} \mathrm{C}$, then 71, $75 \%$; b) $\mathrm{LiBH}_{4}$, wet $\mathrm{Et}_{2} \mathrm{O}, 84 \%$; c) $\mathrm{PPh}_{3}$, imidazole, $\mathrm{I}_{2}, 96 \%$; d) $\mathrm{LiEt}_{3} \mathrm{BH}$, then $\mathrm{H}_{2} \mathrm{O}_{2}, \mathrm{NaOH}, 98 \%$; e) $10 \% \mathrm{Pd} / \mathrm{C}, 10 \% \mathrm{HCO}_{2} \mathrm{H}$ in $\mathrm{MeOH}, 93 \%$; f) Swern oxidation, then addn. of $\mathrm{Ph}_{3} \mathrm{P}=\mathrm{C}\left(\mathrm{CH}_{3}\right) \mathrm{CO}_{2} \mathrm{Et}, 82 \%$; g) DIBAL, DCM, $-78{ }^{\circ} \mathrm{C}, 97 \%$, h) $\mathrm{MnO}_{2}, \mathrm{DCM}, 91 \%$; i) ${ }^{\mathrm{c}} \mathrm{Hex}_{2} \mathrm{BCl}$, $10 \mathrm{Me}_{2} \mathrm{Net},-78{ }^{\circ} \mathrm{C}$ to $-20{ }^{\circ} \mathrm{C}$, then $\mathrm{H}_{2} \mathrm{O}_{2}$, MeOH, pH 7 buffer, $78 \%$; j) Me 2 BuSiOTf, collidine, $98 \%$; k) $\mathrm{LiBH}_{4}, \mathrm{THF},-78^{\circ} \mathrm{C}$, then $\mathrm{NaIO}_{4}$; l) $\mathrm{NaBH}_{4}, \mathrm{MeOH}, 92 \%$; m) see c), $96 \%$; n) homo-allyl-MgBr, CuBr*DMS, THF, $-78{ }^{\circ} \mathrm{C}$ to $-20{ }^{\circ} \mathrm{C}$, then o) catecholborane, THF then aq. $\mathrm{H}_{2} \mathrm{O}_{2}$ at $0{ }^{\circ} \mathrm{C}, 53 \%$ over 2 steps; p) PDC, wet DMF, then $\mathrm{CH}_{2} \mathrm{~N}_{2}, 82 \%$; q) LDA, THF, then 80, HMPA, $71 \%$; r) DMSO, DCC, pyr-HCl, $89 \%$; s) DBU, DCM, rt, then $\mathrm{BrCCl}_{3}, 0{ }^{\circ} \mathrm{C}, 92 \%$; t) TBAF, THF, then u) $\operatorname{Pd}(\mathrm{OAc})_{2}$, $15 \mathrm{~K}_{2} \mathrm{CO}_{3}, \mathrm{MeCN}, 44 \%$ over 2 steps; v) NaI, $\mathrm{HCl}$, acetone, $82 \%$.

Bromide 70 (available in 4 steps from (2R)-methyl 3-hydroxy-2-methylpropionate) was transformed into its organocopper complex and used in an asymmetric conjugate addition to oxazolidinone $\mathbf{7 1},{ }^{85}$ to yield the 1,3-anti dimethyl array $\mathbf{7 2}$. Reductive cleavage of the auxiliary, reduction and cleavage of the benzyl ether 20 yielded alcohol 73, that was homologated to aldehyde 74. Interestingly, the authors of this paper do not comment on racemization in the $\alpha$-position, ${ }^{86}$ which has been discussed under 2.1.3. Further elaboration of the side chain utilizing an anti-aldol process as described by Paterson ${ }^{87}$ with an $(S)$-ethyl lactate derived auxiliary $\mathbf{7 5}$ proceeded smoothly via the $E(\mathrm{O})$-boron enolate and a closed transition state. After ${ }_{25}$ TBS-protection of the alcohol, the auxiliary was reductively removed and then periodate cleavage of the vic-diol, followed by iodination giving iodide 77 . The chain was then elongated to the ester 78. In the original report, this chain elongation is depicted using allyl magnesium bromide, however, the homoallyl Grignard 
reagent was used in this synthesis. The enolate of this ester was condensed with amino aldehyde 80, which is available from starting material 49 in nine steps (see also scheme 5). Immediate oxidation provided enol ester 81. Removal of the Fmoc protecting group with DBU triggered the spontaneous cyclization to an intermediate 5 5,6-dihydropyridone (see also compound 52, scheme 5), that was oxidized upon addition of bromotrichloromethane, yielding $\mathbf{8 2}$ after TBS deprotection. The key step of this reaction sequence is the oxidation of $\mathbf{8 2}$ under buffered Saegusa ${ }^{88}$ conditions with palladium acetate. The intermediate quinone methide reacts in an intramolecular conjugate addition leading exclusively to tetrahydropyran $\mathbf{8 4}$.

${ }_{10}$ Cleavage of the MOM-ether releases (+)-sambutoxin (27) in overall 35 steps with 26 steps in the longest linear sequence. This sequence combines an interesting and high yielding cyclization strategy via enol ester $\mathbf{8 1}$ with a 1,4-addition to a quinone methide after Saegusa oxidation. It was shown that this strategy is also applicable for the synthesis of funiculosin dimethyl ether. ${ }^{89}$

15

\subsubsection{Total synthesis of (+)-apiosporamide and YM-215343 using a $\beta$-lactam precursor}

In 2005 Williams et al. disclosed a stereoselective total synthesis of (+)apiosporamide (17) and YM-215343 (18) based on a further development of their 20 acylation/cyclisation technique already discussed for tenellin (6) (scheme 5) and ilicicolin H (14) (scheme 6). ${ }^{36}$

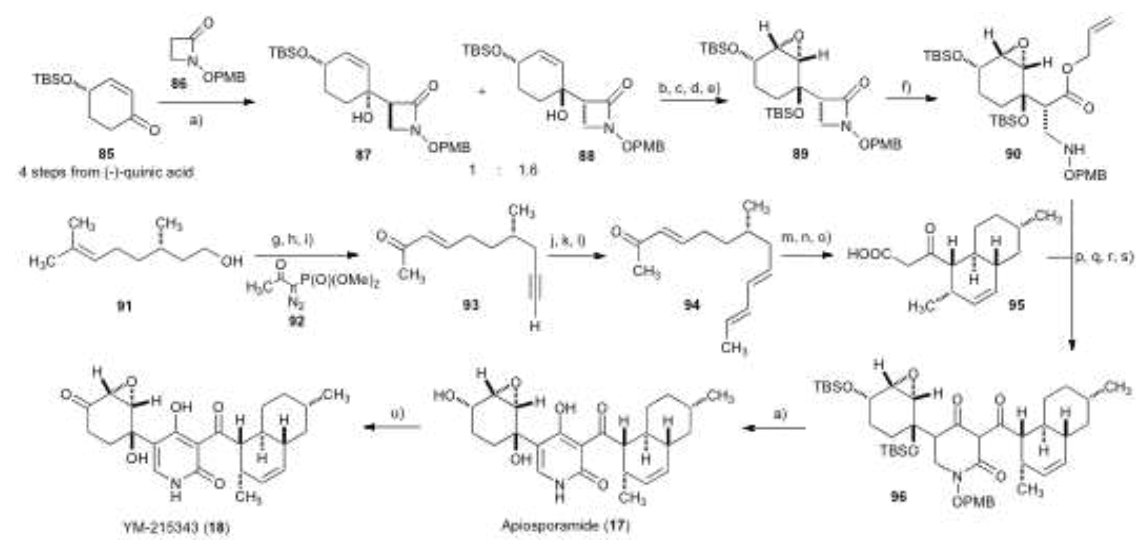

Scheme 10 Enantioselective total synthesis of (+)-apiosporamide (17) and YM-215343 (18). Conditions: a) $86+\mathrm{KHMDS}$, THF, $-78^{\circ} \mathrm{C}$, then $\mathbf{8 5}, 97 \%$, d.r. $1.6: 1$; b) TBS-protection; c) TBAF, 0 ${ }^{\circ} \mathrm{C}, 98 \%$; d) $m \mathrm{CPBA}, \mathrm{DCM}, \mathrm{NaHCO}_{3}, 54 \%$; e) TBSCl, imidazole, DCM, quant.; f) $n \mathrm{BuLi}$, allyl 25 alcohol, $-78{ }^{\circ} \mathrm{C}$ to rt, $80 \%$; g) cat. TEMPO, PhI(OAc) 2 , DCM, 70\%; h) 92, $\mathrm{K}_{2} \mathrm{CO}_{3}, \mathrm{MeOH}, \mathrm{rt}, 82 \%$; i) cat. $\mathrm{OsO}_{4}, \quad \mathrm{~K}_{3} \mathrm{Fe}(\mathrm{CN})_{6}, \quad \mathrm{~K}_{2} \mathrm{CO}_{3}, \quad t \mathrm{BuOH} / \mathrm{H}_{2} \mathrm{O}, 94 \%$, then $\mathrm{NaIO}_{4}$, aq. THF, then $\mathrm{H}_{3} \mathrm{CC}(\mathrm{O}) \mathrm{CH}_{2} \mathrm{P}(\mathrm{O})(\mathrm{OMe})_{2}, \mathrm{~K}_{2} \mathrm{CO}_{3}, 91 \%$, E/Z 13:1; j) $\mathrm{Cp}_{2} \mathrm{Zr}(\mathrm{H}) \mathrm{Cl}, \mathrm{DCM}$, rt, then $\mathrm{I}_{2}, 77 \%$; k) $(E)-$ $\mathrm{BrZnCH}=\mathrm{CHCH}_{3}, \mathrm{THF} / \mathrm{Et}_{2} \mathrm{O} /$ pentane, $-30{ }^{\circ} \mathrm{C}$ to $\mathrm{rt} ; 74 \%$; 1) DMP, py, DCM, 90\%; m) EtAlCl $\mathrm{H}_{2}$, toluene, $-78{ }^{\circ} \mathrm{C}$ to rt, $72 \%$, $>97: 3$ d.r.; n) LiHMDS, THF, $-78{ }^{\circ} \mathrm{C}$ to $0{ }^{\circ} \mathrm{C}$, then HMPA at $-78{ }^{\circ} \mathrm{C}$, then

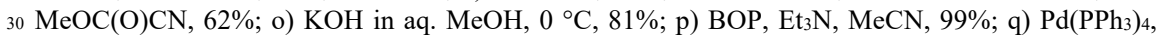
pyrrolidine, DCM, 85\%; r) BOP, DCM, DBU, 56\%; s) $\mathrm{SmI}_{2}, \mathrm{THF}, 98 \%$; t) $\mathrm{BrCCl}_{3}$, tetramethylguanidine, $65 \%$ then $\mathrm{HF}^{*}$ pyr, THF, 75\%; u) DMP, DCM, $92 \%$.

Enone 85 was reacted in an aldol reaction with $\beta$-lactam 86 yielding a separable 1:1.6 mixture of diastereomeric tertiary alcohols $\mathbf{8 7}$ and $\mathbf{8 8}$. Compound $\mathbf{8 8}$ was TBS${ }_{35}$ protected and then selectively deprotected to conduct a Henbest ${ }^{90}$ cis-epoxidation, 
followed by TBS-reprotection, yielding epoxide 89. Cleavage of the $\beta$-lactam ring with lithiated allyl alcohol resulting in allylic ester $\mathbf{9 0}$ which is related to compounds 50 and 51 (scheme 5). Acylation of 90 was conducted after BOP activation of enantiomerically pure acid 95, which was obtained from (-)-citronellol (91) in a nine ${ }_{5}$ step sequence. Briefly, homologation with the Ohira-Bestmann reagent ${ }^{91} 92$ after oxidation of the alcohol, bis-hydroxylation, oxidative cleavage and HWE reaction gave ketone 93, that was hydrozirconated and quenched with iodine with concomitant reduction of the ketone. ${ }^{92}$ Negishi cross coupling delivered the diene, followed by oxidative regeneration of the enone 94. Diels-Alder reaction and C10 acylation according to Mander ${ }^{93}$ gave acid 95. After cleavage of the allyl protecting group, ring closure was achieved by activation of the acid in the presence of DBU. Reductive cleavage of the N-protecting group with samarium iodide, ${ }^{94}$ oxidation of the pyridone ring with bromotrichloromethane and TBS-deprotection unveiled $(+)$ apiosporamide (17), which was further oxidized with Dess-Martin periodinane ${ }^{95}$ to 15 YM-215343 (18), both being the antipodes of the corresponding natural products. This sequence displays an impressive approach towards pyridone alkaloids. It showcases the utility of $\beta$-lactams in the construction of highly functionalized pyridone structures.

\section{2.1.6 Total synthesis of YCM1008A (32) by intramolecular $N$-Michael addition- elimination}

The total synthesis of YCM1008A (32) has been achieved using an internal cyclization strategy giving mixtures of syn and anti diastereomers that were separated. ${ }^{59}$ Finally, camphanic esters had to be synthesized to facilitate separation

25 of diastereomers due to low selectivity in the transformations. However, using this strategy, the relative and absolute configuration of YCM1008A (32) were sucessfully assigned in the end.

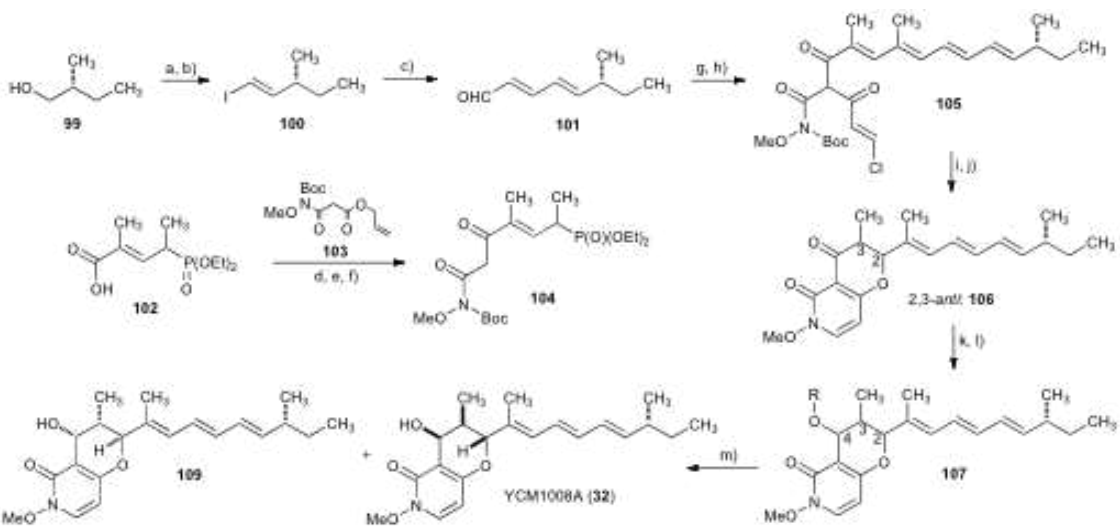

Scheme 11 Total synthesis of YCM1008A (32). Conditions: a) TEMPO, $\mathrm{NaOCl}, \mathrm{KBr}, \mathrm{NaHCO}_{3}$, DCM, then b) $\mathrm{CrCl}_{3}, \mathrm{LiAlH}_{4}, \mathrm{CHI}_{3}, \mathrm{THF}, 33 \%$ (2 steps); c) (E)-CHOCH=CHSn$(n \mathrm{Bu})_{3}$, $30 \mathrm{PdP}\left(\mathrm{Ph}_{3}\right)_{2} \mathrm{Cl}_{2}$, CuI, DMF, 60\%; d) (COCl) 2 , DMF, DCM, then e) $i \mathrm{PrNEt}_{2}, \mathrm{MgCl}_{2}, 103,74 \%$ (2 steps); f) $\mathrm{Pd}\left(\mathrm{PPh}_{3}\right)_{4}, \mathrm{HCO}_{2} \mathrm{H}, \mathrm{Et}_{3} \mathrm{~N}, \mathrm{THF}, 87 \%$; g) 104, NaH, THF, 25\%; h) (E)-3-chloroacryloyl chloride, $i \mathrm{PrNEt}_{2}, \mathrm{MgCl}_{2}$, THF, then i) Amberlyst 15, DCM, 34\% in two steps, 2,3 syn / 2,3 anti $\left.(1: 1) ; \mathrm{j}\right)$ $\mathrm{TiCl}(\mathrm{O} i \mathrm{Pr})_{3}, \mathrm{Cl}\left(\mathrm{CH}_{2}\right)_{2} \mathrm{Cl}, 75 \%$ from 2,3 anti-intermediate, 34\% from syn-intermediate; k) DIBAL, DCM, $-78{ }^{\circ} \mathrm{C}$, mixture of 4 stereoisomers, 67\%; 1) (-)-camphanoyl chloride, py, DCM, separation; $35 \mathrm{~m}) \mathrm{NaOMe}, \mathrm{MeOH}, 79 \%$. 
Alcohol 99 was oxidized and subjected to a Takai reaction. ${ }^{96}$ The vinyliodide $\mathbf{1 0 0}$ was used in a Stille coupling ${ }^{97}$ giving aldehyde 101 which was further modified in a Horner-Wadsworth-Emmons reaction with phosphonate 104. Acylation of the intermediate diketo compound resulted in polyene $\mathbf{1 0 5}$ that was directly cyclized to 5 mixtures of syn- and anti- $\gamma$-pyrones. After separation of syn and anti isomers, deprotection of the hydroxamic acid induced a Michael addition-elimination reaction resulting in both anti-isomers 106. Reduction of the ketone gave a complex mixture of all four possible isomers that were separated after esterification with (-)champhanoyl chloride. The separated diastereomers were then deprotected and their

10 spectral data compared with those of the natural product. YCM1008A (32) was found to be identical in all aspects with $\left(2 R, 3 R, 4 S, 8^{\prime} R\right)$ pyridone (32). The key steps of this synthesis are the sequential Michael-addition to a $\gamma$-pyrone that is subjected to another Michael-addition-elimination reaction to furnish pyridone 106 from starting material 105. Due to low selectivities, tedious purification procedures and 15 modifications were necessary.

\subsection{Modifications of the pyridone core}

Different strategies have been developed to modify the pyridone core structure, either by metalation and electrophile quenching, by Knoevennagel-ene cascades or 20 cross couplings.

\subsubsection{Total syntheses of atpenins and harzianopyridone by repeated metalation of 2- chloropyridine}

The first total synthesis for one member of the atpenins was reported in 1994. It is 25 an interesting reaction sequence featuring a "clockwise" functionalization of 2chloropyridine 110 via directed metalations, electrophile trapping and the halogen dance reaction (scheme 12)..$^{98}$

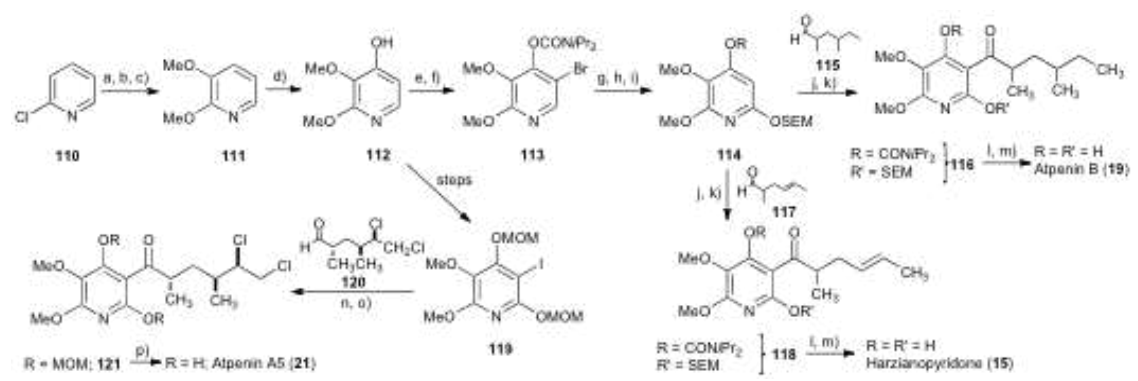

Scheme 12 Total syntheses of atpenin B (19), harzianopyridone (15) and atpenin A5 (21). Conditions: a) LDA, $\mathrm{B}(\mathrm{OMe})_{3}$, then $\mathrm{CH}_{3} \mathrm{C}(\mathrm{O}) \mathrm{OOH}, 65 \%$; b) MeI, NaH, DMF, rt, $93 \%$; c) $\mathrm{MeOH}$, $30 \mathrm{NaH}, \mathrm{DMF}, 80{ }^{\circ} \mathrm{C}, 86 \%$; d) $n \mathrm{BuLi}, \mathrm{B}(\mathrm{OMe})_{3}, m \mathrm{CPBA}$, THF, $-78^{\circ} \mathrm{C}, 64 \%$; e) $\mathrm{Ag}_{2} \mathrm{CO}_{3}, \mathrm{ClCON} \mathrm{Pr}_{2}$, $70 \%$; f) $n \mathrm{BuLi}, \mathrm{THF},-78{ }^{\circ} \mathrm{C}$, then BrCN, $93 \%$; g) LDA, THF, $-40{ }^{\circ} \mathrm{C}$, cat $\mathrm{Br}_{2}$, then EtOH, $73 \%$; h) $n$ BuLi, THF, $-70{ }^{\circ} \mathrm{C}, \mathrm{B}(\mathrm{OMe})_{3}$, then $\mathrm{CH}_{3} \mathrm{COOOH}, 63 \%$; i) $\mathrm{NaH}, \mathrm{SEM}-\mathrm{Cl}, \mathrm{THF}, 84 \%$; j) $n \mathrm{BuLi}$, Diisopropylamine (cat.), then 75; $80 \%$; k) PCC, DCM, 70\%; 1) KOH, MeOH; m) HCl, MeOH, 78 $\%$ (2 steps).

${ }_{35}$ Chloropyridine 110 was first metalated in 3-position followed by trapping with trimethylborate, oxidation to the phenol, ${ }^{99}$ methylation and nucleophilic substitution of the chlorine yielding dimethoxypyridine 111. Again, selective metalation and subsequent boronation/oxidation gave rise to phenol 112. Suitable carbamate 
protection followed by metalation and trapping with cyanogen bromide gave 5brominated pyridine 113. This pyridine was subjected to the halogen dance reaction, generating an equibrium between the 5-bromo-6-lithio and the 5-lithio-6-bromo species which is shifted towards the more stable 5-lithio-6-bromo compound. ${ }^{96}$ ${ }_{5}$ Trapping with the trimethylborate/oxidation sequence affords pyridine 114 after SEM-protection. Metalation of pyridine 114, trapping with aldehyde 115 and oxidation gives the acylated pyridine 116. Cleavage of the protecting groups releases racemic atpenin B (19). The same sequence was also applied to the total synthesis of harzianopyridone (15) by trapping of the metallated pyridine 114 with aldehyde 10 117. $^{34}$

A slightly modified but still similar protocol was used for the stereoselective construction of atpenin A5 (21). ${ }^{42}$ MOM protecting groups were used insted of the carbamate to avoid strongly basic deprotection conditions which may result in racemization of the $\alpha$ stereogenic center in 21. However, addition to the aldehyde $15 \mathbf{1 2 0}$ is conducted under strongly basic conditions. Iodine was used instead of bromine for the halogen dance reaction and metalation of the pyridine core was achieved by lithium halogene exchange in compound 119. Trapping of metallated 119 with aldehyde 120, oxidation and deprotection of $\mathbf{1 2 1}$ finished the sequence to atpenin A5 (21).

20

\subsubsection{Racemic total synthesis of cordypyridones A and B utilizing a Hal-Li exchange}

In 2009, a racemic total synthesis of cordypyridones A (42a) and B (42b) also known as 8-methylpyridoxatin (42) was published. The authors presented a short sequence based on a pyridone core modification. ${ }^{76}$

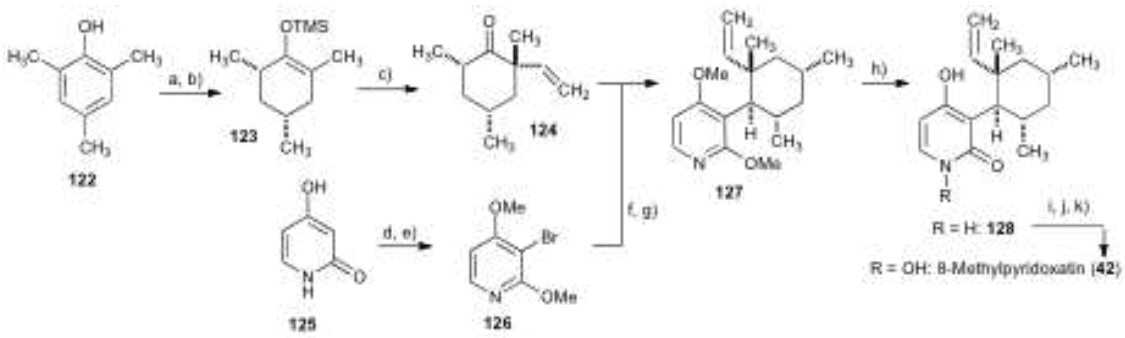

${ }_{25}$ Scheme 13 Total synthesis of 8-methylpyridoxatin (42). Conditions: a) Rh-catalyst on $\beta-75$ zeolite, $\mathrm{H}_{2}$, EtOH, 100 bar, $175{ }^{\circ} \mathrm{C}, 1 \mathrm{~h}, 82 \%$; b) LDA, TMSCl, THF, $-78{ }^{\circ} \mathrm{C}, 86 \%$; c) $\mathrm{GaCl}_{3}$, THF, ethynyltrimethylsilane, rt, $5 \mathrm{~min}, 87 \%$; d) $\mathrm{NBS}$, $\mathrm{MeCN}$, reflux, then e) $\mathrm{MeI}, \mathrm{Ag}_{2} \mathrm{CO}_{3}, \mathrm{CHCl}_{3}, 3 \mathrm{~d}$, $42 \%$ over 2 steps; f) $n \mathrm{BuLi}$, THF, $-78{ }^{\circ} \mathrm{C}$, then 112 , then chlorooxoacetate, $1 \mathrm{~h}, 61 \%$; g) AIBN, $\mathrm{Bu}_{3} \mathrm{SnH}$, toluene, heat, $18 \mathrm{~h}, 86 \%$; h) MeMgI, neat, $165^{\circ} \mathrm{C}, 2 \mathrm{~h}, 72 \%$; i) HMDS, TMSCl, reflux, $24 \mathrm{~h}$ 30 then j) $\mathrm{MoO}_{5} *$ py*HMPA, DCM, $24 \mathrm{~h}$; k) Na 4 EDTA, $\mathrm{H}_{2} \mathrm{O} / \mathrm{EtOAc}, \mathrm{rt}, 2 \mathrm{~h}, 61 \%$ over three steps.

The reaction started with hydrogenation of phenol 122 with a zeolite-supported rhodium catalyst, giving a meso-ketone ${ }^{100}$ that was converted into the TMS enolate 123. The vinyl substituent was then installed syn to the other methyl substituents by coupling of $\mathbf{1 2 3}$ with ethynyl-TMS in the presence of gallium trichloride, ${ }^{101}$ yielding 35 a $>9: 1$ mixture of diastereoisomers $\mathbf{1 2 4}$. Next, commercially available pyridone $\mathbf{1 2 5}$ was selectively brominated and then converted to the bis-methyl ether 126. Coupling of the fragments was achieved by Br-Li exchange followed by nucleophilic attack to the ketone. The alcoholate function was directly trapped with chlorooxoacetate producing an oxalate moiety. This was removed in a Dolan-MacMillan 
deoxygenation ${ }^{102}$ proceeding via a planar C-centered radical, which is intercepted with tributyl tin hydride from the less hindered side (not shielded by axial methyl group). The bis methyl ether $\mathbf{1 2 7}$ was deprotected by heating in neat methyl Grignard reagent yielding pyridone $\mathbf{1 2 8}$ that was $N$-oxidized according to ${ }_{5}$ Sammes ${ }^{103,} 104$ giving a separable mixture of the atropisomers of 8 methylpyridoxatin (42) (Cordypyridone A (42a) and B (42b)).

The sequence is certainly attractive due to its shortness combining a fast and efficient coupling of both fragments via $\mathrm{Li}-\mathrm{Br}$ exchange with an interesting access to the functionalized cyclohexyl-moiety by utilizing zeolite assisted hydrogenation.

${ }_{10}$ Key step of this sequence was a lithium halogen exchange and attack of the pyridyl anion on a vinyl ketone terminated by trapping with methyl chlorooxoacetate.

\subsubsection{Racemic total synthesis of pyridoxatin, leporin $A$ and fusaricide}

In 1994 Snider et al. disclosed their first report on tandem Knoevennagel15 electrocylic reactions to construct functionalized 2-pyridones. ${ }^{73} \mathrm{We}$ have already discussed the useful intermediate $o$-quinone methides ${ }^{105}$ in the construction of sambutoxin (27) (scheme 9, 28) that were utilized in this sequence.

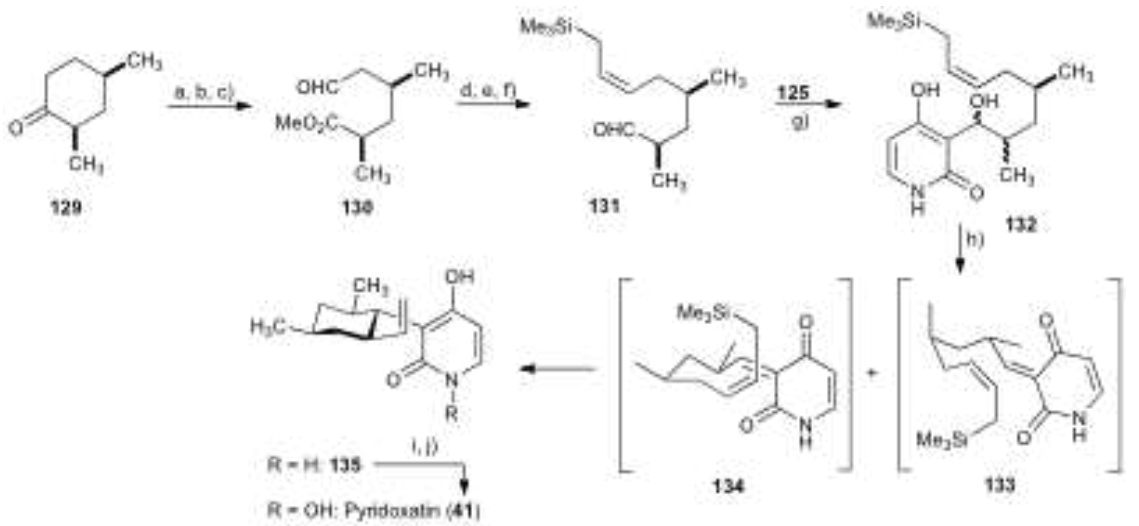

Scheme 14 Total synthesis of pyridoxatin (41). Conditions: a) LDA, TMSCl, 75\%; b) $\mathrm{O}_{3}, \mathrm{Me}_{2} \mathrm{~S}$, then c) $\mathrm{CH}_{2} \mathrm{~N}_{2}, 72 \%$; d) $\mathrm{Ph}_{3} \mathrm{P}=\mathrm{CHCH}_{2} \mathrm{SiMe}_{3}, 73 \%$; e) DIBAH, $80 \%$; f) Swern oxidation, $80 \%$; g)

20 113, piperidinium acetate, EtOH, reflux, $12 \mathrm{~h}$, then $\mathrm{h}) \mathrm{Me}_{2} \mathrm{AlCl}, \mathrm{DCM}, 12 \mathrm{~h}, \mathrm{rt}, 17 \%(1: 1 \mathrm{mixture}$ of atropisomers); i) HMDS, TMSCl, reflux, 24h then j) MoOs*py*HMPA, DCM, 24 h, 44\% over 2 steps.

Racemic cyclohexanone 129, obtained by cis-hydrogenation of 2,4-dimethylphenol and Jones oxidation, was converted into its TMS-enolate, ozonolyzed and 25 methylated to aldehydo ester 130, containing ca. $10 \%$ of its diastereoisomer. After chain elongation by a Wittig reaction and a reduction oxidation sequence, allylsilane 131 with a nucleophilic double bond was obtained. Condensation of 131 with dihydroxypyridine 125 gave a complex mixture of diastereomers 132, in which unfortunately the relative relation of the methyl groups was scrambled in the 30 reaction conditions. Treatment of the mixture with excess dimethyl aluminium chloride led to o-quinone methides $\mathbf{1 3 3}$ and $\mathbf{1 3 4}$ that reacted in a stereospecific intramolecular ene reaction in $\mathbf{1 3 4}$ giving the desired racemic pyridone $\mathbf{1 3 5}$ with all substituents in the equatorial position. After removal of the undesired product resulting from transition state $\mathbf{1 3 3}$, the pyridone $\mathbf{1 3 5}$ was oxidized by the Sammes ${ }^{103}$, ${ }_{35}{ }^{104}$ procedure to the hydroxamic acid pyridoxatin (41), that was obtained as a 
racemic mixture of atropisomers. This reaction sequence provided a rapid access to racemic 3-cyclohexylpyridones by combining a Knoevenagel and an ene reaction, although in moderate yield.

In 1996 Snider and Lu envisaged to synthesize racemic leporin A (33) utilizing a 5 tandem Knoevenagel condensation - inverse electron demand intramolecular hetero Diels-Alder reaction. ${ }^{69}$ Despite extensive investigations on similar reactions by Tietze $^{105}$ leading to trans-ring fusions, for leporin A (33) the Diels-Alder reaction would require to yield a cis-ring fusion.

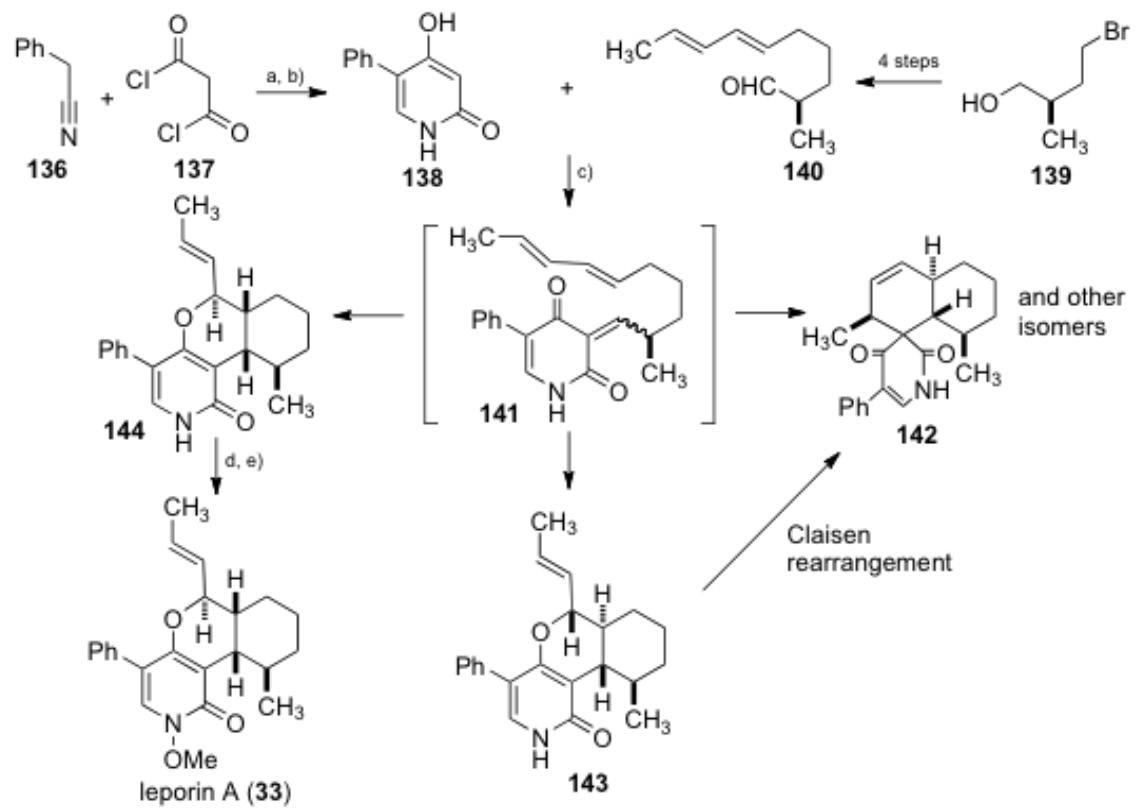

Scheme 15 Total synthesis of leporin A (33). Conditions: a) $4 \mathrm{~d}, 25^{\circ} \mathrm{C}, 58 \%$; b) $\mathrm{H}_{2}, \mathrm{Pd} / \mathrm{C}, \mathrm{EtOH}, 60$ $10{ }^{\circ} \mathrm{C}, 98 \%$; c) $\mathrm{Et}_{3} \mathrm{~N}$, EtOH, reflux; $35 \%$ of 144; d) HMDS, TMSCl, reflux, $24 \mathrm{~h}$ then $\mathrm{MoO}_{5}{ }^{*}$ py*HMPA, DCM, 24 h, 57\% over 2 steps; e) NaOMe, MeI, 77\%.

Condensation of phenylacetonitrile 136 with malonylchloride 137 followed by hydrogenolysis provided pyridone 138. ${ }^{106}$ Aldehyde $\mathbf{1 4 0}$ was obtained from alcohol 139 in four steps. Condensation of pyridone 138 and aldehyde 140 under basic 15 conditions in refluxing ethanol generated intermediate $o$-quinone methide 141, that reacted amongst other available reaction pathways preferentially to the depicted compounds 144 with the desired cis-ring fusion (35\%), 143 with the trans-ring fusion (7\%) and different spirocycles $142(32 \%)$, that were shown to be products of a Claisen rearrangement of 143, whereas the cis-fused pyridone 144 did not 20 rearrange in this manner. $N$-oxidation ${ }^{103,104}$ followed by methylation yielded leporin A (33) in racemic form in only ten steps. This reaction sequence provides rapid access to tricyclic pyridone alkaloids using readily available and inexpensive starting materials combining them in a tandem one-pot Knoevenagel-electrocylic condensation to obtain $c i s$-fused decalin systems.

${ }_{25}$ A comparable approach to the fused tricyclic ring system of fusaricide (35) was also developed in the group of Snider, combining a Knoevenagel condensation with a hetero Diels-Alder reaction. Unfortunately, due to the unfavorable substitution pattern of the diene for this type of reaction, the yields were poor $(8 \%$ of the desired 
adduct). ${ }^{107}$

\subsubsection{Cross coupling reactions in the construction of functionalized pyridones}

Different approaches to modified pyridone alkaloids using palladium catalyzed 5 coupling reactions have been described, though none of these approaches has ultimately led to a completed total synthesis of a member of this class of natural products. Two examples will be presented in this section, as they provide interesting chemistry on the way to modified pyridone alkaloids.

The first example is taken from the work of Fürstner et al. describing the synthesis 10 of TMC-69-6H (152), ${ }^{44}$ the hydrogenated congener of the natural product phosphatase inhibitor TMC-69 (22).

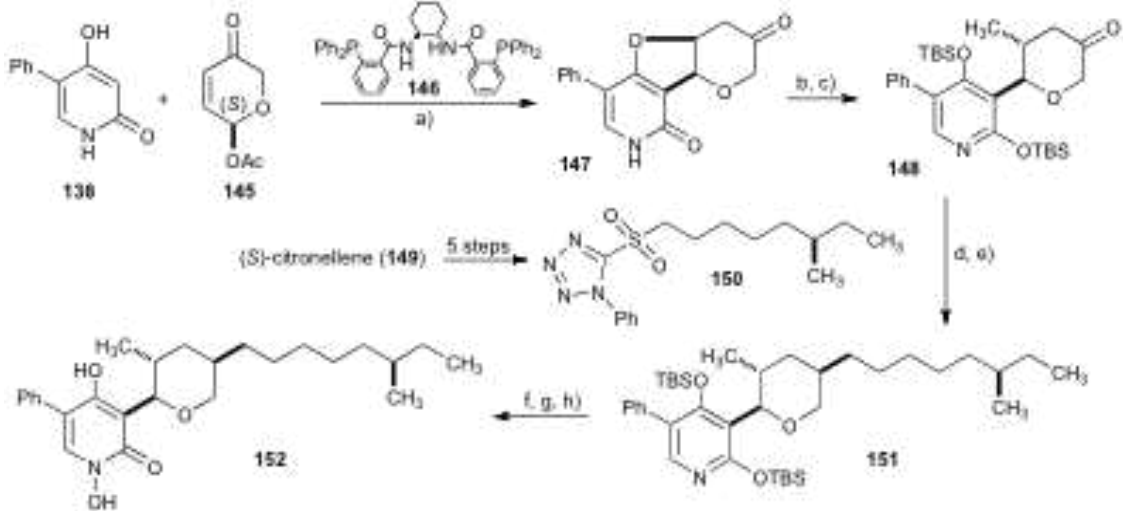

Scheme 16 Total synthesis of TMC-69-6H (152). Conditions: a) [\{(allyl)PdCl $\left.\}_{2}\right](0.5 \%), 146$ (1.5\%) Et 3 N, DMF, 65\%, 96\% ee; b) TBSCl, Et $3 \mathrm{~N}, 18 \mathrm{~h}, 78 \%$; c) $\mathrm{Me}_{2} \mathrm{CuLi}, \mathrm{THF},-70{ }^{\circ} \mathrm{C}$; d) LiHMDS, 150, 69\% over 2 steps; e) $\mathrm{H}_{2}, \mathrm{Pd} / \mathrm{C}$, EtOH; f) TBAF, THF, 69\% over two steps; g) 15 HMDS, TMSCl, reflux, then h) $\mathrm{MoO}_{5}{ }^{*}$ py*HMPA, DCM, then sat. aq. EDTA-Na, EtOAc, $61 \%$ over 2 steps.

Enantioenriched unsaturated ketone 145 was C-coupled to the enol site of the pyridone 138 in the presence of chiral diphosphane $\mathbf{1 4 6}^{108}$ with low catalyst loadings of $\{(\text { allyl }) \mathrm{PdCl}\}_{2}$ in high enantiomeric excess. At the same time, a spontaneous 1,420 addition of the hydroxy group to the enone was observed. Retro-Michael reaction in the presence of oxophilic TBS-chloride regenerated the unsaturated ketone that was transformed in a conjugate addition to trans-ketone 148. Julia-Kocienski olefination $^{109}$ using sulfone $\mathbf{1 5 0}$ followed by hydrogenation furnished a separable mixture of $\mathbf{1 5 1}$ and its epimer. Deprotection and oxidation according to Sammes 25 procedure ${ }^{103,104}$ furnished TMC-69-6H (152) in enantiopure form. The unique palladium catalyzed stereoselective allylation 1,4-addition sequence with a phenol derived substrate followed by the rapid assembly of the target structures constitute the cornerstones of this impressive synthesis, which is certainly amenable to efficiently access other related structures.

30 The last synthetic approach remaining to be discussed is the nice study towards a biomimetic synthesis published by Robert Adlington et al. ${ }^{110}$ Though the sequence for the preparation of the pyridone core is similar to the one initially conducted by Williams in their tenellin (6) synthesis (see scheme 5), we have grouped this approach as a pyridone core functionalization, because a Suzuki-coupling is applied 35 to generate the biaryl axis. Moreover, an acyl nitrone intermediate is cyclized with 
an enone in a 1,3 dipolar cycloaddition as proposed for the biosynthesis. Interestingly, the dipolarophil in this putative biosynthesis would be cephalosporolide B (153), itself a natural product, that has not yet been isolated from Beauveria bassiana, from which pyridomacrolidin (13) was isolated. It has however 5 been found in the fungus Cephalosporicum aphidicola. ${ }^{111}$

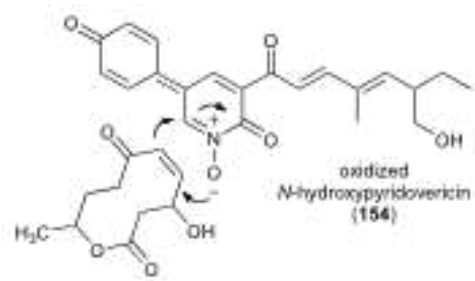

Cephalosponalde B (153)

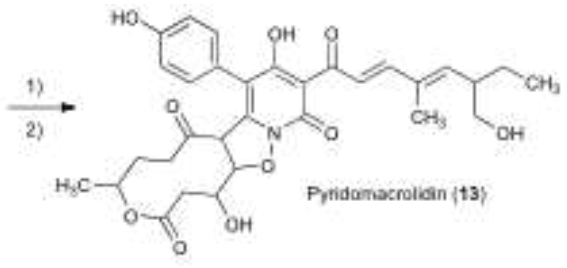

1) 1,3-dipolar cycloaddition; 2) raaromaization
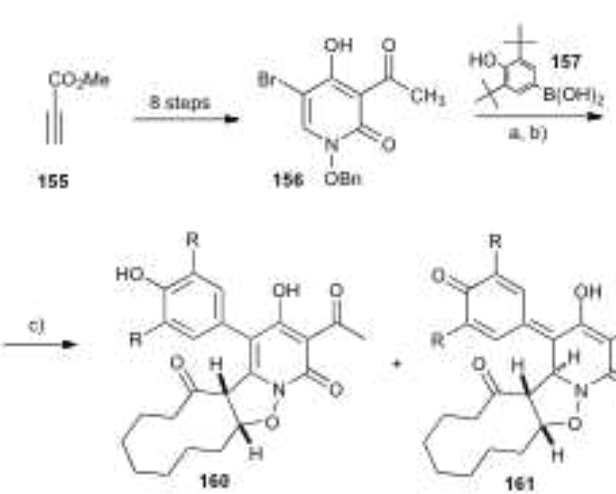

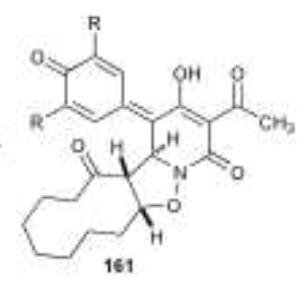

161
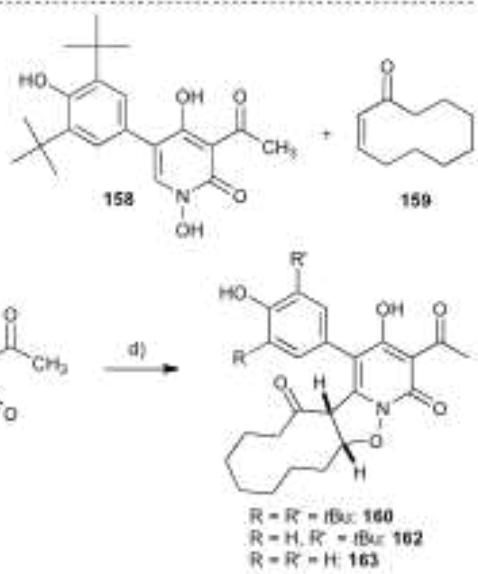

Scheme 17 Biomimetic studies towards pyridomacrolidin (13). Conditions: a) $\mathrm{Pd}\left(\mathrm{PPh}_{3}\right)_{4}, \mathrm{Na}_{2} \mathrm{CO}_{3}$, THF, reflux, 12h, 71\%; b) $\mathrm{H}_{2}$, Pd/C, dioxane, $90 \%$; c) $\mathrm{PhI}(\mathrm{OAc})_{2}$, DCM, reflux, 24 h; 60 \% 160/161 1:1.4; $5 \%$ other minor isomers; d) $\mathbf{1 6 1}, \mathrm{AlCl}_{3}$, toluene, $95^{\circ} \mathrm{C}, 2 \mathrm{~d}, 40 \% \mathbf{1 6 0} / \mathbf{1 6 2} / \mathbf{1 6 3} 5: 2: 1$.

Parts of the proposed biosynthesis of pyridomacrolidin (13) are shown in the upper 10 part of scheme 17. A quinonoid nitrone 154 - obtained by oxidation of $N$ hydroxypyridovericin - would react in a 1,3-dipolar cycloaddition with cephalosporolide B 153 and then rearomatize to give 13. This interesting proposal was examined using simplified and stabilized analogs of 153 and 154. First, heterocycle 156 was obtained from starting material 155 in 8 steps using the 15 previously described Dieckmann cyclization strategy in $12 \%$ overall yield. ${ }^{18} \mathbf{1 5 6}$ was coupled to boronic acid $\mathbf{1 5 7}$ with tert-butyl protected ortho-positions to prevent side reactions after quinone methide formation. Interestingly, this is one of the rare examples to construct the biaryl axis of e.g. 158 using cross coupling chemistry. Next, oxidation with $\mathrm{PhI}(\mathrm{OAc})_{2}$ at high temperatures generated a quinonoid nitrone 20 that reacted with model compound 159 regio- and stereospecific generating the cisfused cycloadducts $\mathbf{1 6 0}$ and $\mathbf{1 6 1}$ in 60\% yield and trans-fused cycloadducts (not shown) in only $5 \%$ yield. Addition of the oxygen always occured on the $\beta$-carbon of the enone. It is interesting to note that quinone methide $\mathbf{1 6 1}$ is in fact a tautomer of 160. Di-de-tert-butylation ${ }^{112}$ was achieved starting from compound 161 under harsh ${ }_{25}$ Friedel-Crafts conditions, but no full conversion could be obtained. The same reaction conditions applied to phenol $\mathbf{1 6 0}$ proceeded even more slowly and in lower 
yields. However, this study propose that the proposed biosynthesis might be occuring via 1,3 dipolar cycloaddition of quinonoid nitrones to enones resulting in the formation of architecturally intriguing compounds like e.g. pyridomacrolidin (13).

\section{s 3 Conclusions}

Pyridone alkaloids constitute a remarkable class of secondary metabolites. Due to their diversity, many different biological effects of these compounds have been identified, which may however not always be related to their original biological function. Their versatile and diverse structures resulting from different 10 modifications in all positions of the pyridone core render these compounds a fascinating playground for synthetic chemists for many decades. Despite the innovative synthetic approaches that have been developed to obtain these natural products in totally synthetic form, much work remains to be done for synthetic chemists, as many of the known structures have not been determined in full detail.

15 Likewise, the synthesis of derivatives to generate structure-activity-relationships has not found too much attention. The original biological function of these secondary metabolites remains largely unsolved despite speculations about the metal sequestering properties of hydroxamic acids. Thus, some of these compounds may function as siderophores. ${ }^{73,113}$ Other biological aspects, e.g. the biosynthesis of 20 tenellin, have been clarified in great detail. The oxidative ring expansion mechanism from tetramic acids to generate the pyridone core has been widely accepted. ${ }^{14-115}$ Additionally, hidden pyridone alkaloids have been obtained by activation of silenced gene clusters, coding for PKS-NRPS hybrids. ${ }^{11}$ For these reasons, many further discoveries in this field of research appear to be possible. At the same time, as can

25 be seen from the known structures, many intermediates and further functionalized pyridone alkaloids remain to be identified in biological sources. In this review, we have only discussed the 4-oxygenated 2-pyridones. Other closely related structures such as for example the lycopodium alkaloids have been reviewed ${ }^{116}$ and there are many more related structures incorporating the 2-pyridone core. It is also 30 noteworthy that the 2-pyridone structure can be found in approved drugs like e.g. milrinone, ${ }^{117,118}$ making these compounds and the development of versatile synthetic approaches a junction of natural product and medicinal chemistry.

\section{Acknowledgements}

K. G. is a European Young Investigator (EURYI). We gratefully acknowledge the ${ }_{35}$ SNF (PE002-117136/1) and the DFG (JE 572/1-1) for financial support. 


\section{References}

${ }^{a}$ University of Basel, Department of Chemistry, St. Johanns-Ring 19, CH-4056 Basel, Switzerland.

E-mail:karl.gademann@unibas.ch

51 J. Tuson, J. Chem. Soc., 1864, 17, 195-197.

2 L. Maquenne, L. Philippe, Comptes Rendus Hebdomadaire des Seances de l'Academie des Sciences, 1904, 139, 840-843.

3 S. H. El Basyouni, D. Brewer, and L. C. Vining, Canad. J. Bot., 1968, 46, 441-448.

4 A. G. McInnes, D. G. Smith, Chi-Kit Wat, L. C. Vining, J. L. C. Wright, J. Chem. Soc. Chem.

10 Commun., 1974, 281-282.

5 C.G. Casinovi, G. Grandolini, R. Mercantini, N. Oddo, R. Olivieri, A. Tonolo, Tetrahedron Lett., 1968 , 27, 3175-3178.

6 K. Ando, S. Suzuki, T. Saehi, G. Tamura, K. Arima, J. Antibiot., 1969, 22, 189-194.

7 S. Hayakawa, H. Minato, K. Katagiri, J. Antibiot., 1971, 24, 653-654.

158 H. Wolf, H. Zähner, Arch. Mikrobiol., 1972, 83, 147-154.

9 M. Torres, S. Gil, M. Parra, Curr. Org. Chem., 2005, 9, 1757-1779.

10 G. R. Waller, L. M. Henderson, J. Biol. Chem., 1961, 236, 1186-1191.

11 S. Bergmann, J. Schümann, K. Scherlach, C. Lange, A. A. Brakhage, C. Hertweck, Nat. Chem. Biol., 2007, 3, 213-217.

2012 S. Takahashi, K. Uchida, N. Kakinuma, R. Hashimoto, T. Yanagisawa, A. Nakagawa, J. Antibiot., 1998, 51, 1051-1054.

13 Q. Zhang, A. Rivkin, D.P. Curran, J. Am. Chem. Soc., 2002, 124, 5774-5781.

14 K. L. Eley, L. M. Halo, Z. Song, H. Powles, R. J. Cox, A. M. Bailey, C.M. Lazarus, T. J. Simpson, ChemBioChem, 2007, 8, 289-297.

2515 L. B. Jeffs, G. G. Khachatourians, Toxicon, 1997, 35, 1351-1356.

16 L. M. Halo, J. W. Mar

shall, A. A. Yakasai, Z. Song, C. P. Butts, M. P. Crump, M. Heneghan, A. M. Bailey, T. J. Simpson, C. M. Lazarus, R. J. Cox, ChemBioChem, 2008, 9, $585-594$.

17 L. M. Halo, M. N. Heneghan, A. A. Yakasai, Z. Song, K. Williams, A. M. Bailey, R. J. Cox, C.

30 M. Lazarus, T. J. Simpson, J. Am. Chem. Soc., 2008, 130, 17989-17996.

18 D. R. Williams, S.-Y. Sit, J. Org. Chem., 1982, 47, 2846-2851.

19 J. H. Rigby, M. Qabar, J. Org. Chem., 1989, 47, 5852-5853.

20 Y. Cheng, B. Schneider, U. Riese, B. Schubert, Z. Li, M. Hamburger, J. Nat. Prod., 2004, 67, 1854-1858.

3521 H. J. Jessen, D. Barbaras, M. Hamburger, K. Gademann, Org. Lett., 2009, 11, 3446-3449.

22 Y. Cheng, B. Schneider, U. Riese, B. Schubert, Z. Li, M. Hamburger, J. Nat. Prod., 2006, 69, 436-438.

23 K. Schmidt, U. Riese, Z. Li, M. Hamburger, J. Nat. Prod., 2003, 66, 378-383.

24 K. Schmidt, W. Günther, S. Stoyanova, B. Schubert, Z. Li, M. Hamburger, Org. Lett., 2002, 4, $40 \quad 197-199$.

25 P. Küenzi, S. Kiefer, A. Koryakina, M. Hamburger, Apoptosis, 2008, 13, 364-376.

26 N. R. Irlapati, J. E. Baldwin, R. M. Adlington, G. J. Pritchard, A. R. Cowley, Tetrahedron, 2006, 62, 4603-4614

27 S. Hayakawa, H. Minato, K. Katagiri, J. Antibiot., 1971, 24, 653-654.

4528 M. Matsumoto, H. Minato, Tetrahedron Lett., 1976, 3827-3830.

29 M. Tanabe, S. Urano, Tetrahedron, 1983, 24, 3569-3574.

30 D. R. Williams, M. L. Bremmer, D. L. Brown, J. D'Antuono, J. Org. Chem., 1985, 50, 28092810.

31 C. Dickinson, J. R. Hanson, P. B. Hitchcock, N. Claydon, J. Chem. Soc, Perkin Trans. I, 1989, $50 \quad 1885-1887$.

32 H. G. Cutler, J. M. Jacyno, Agric. Biol. Chem., 1991, 55, 2629-2631.

33 H. Miyadera, K. Shiomi, H. Ui, Y. Yamaguchi, R. Masuma, H. Tomoda, H. Miyoshi, A. Osanai, K. Kita, S. Omura, Proc. Natl. Acad. Sci. U.S.A., 2003, 100, 473-477.

34 F. Trécourt, M. Mallet, O. Mongin, G. Quéguiner, J. Heterocyclic Chem., 1995, 32, 1117-1124.

5535 H. Fujimoto, M. Ikeda, K. Yamamoto, M. Yamazaki, J. Nat. Prod., 1993, 56, 1268-1275.

36 D. R. Williams, D. C. Kammler, A. F. Donnell, W. R. F. Goundry, Angew. Chem. Int. Ed., 2005, 44, 6715-6718.

37 A. A. Alfatafta, J. B. Gloer, J. A. Scott, D. Malloch, J. Nat. Prod., 1994, 57, 1696-1702. 
38 M. Shibazaki, M. Taniguchi, T. Yokoi, K. Nagai, M. Watanabe, K. Suzuki, T. Yamamoto, J. Antibiot., 2004, 57, 379-382.

39 S. Omura, H. Tomoda, K. Kimura, D.-Z. Zhen, H. Kumagai, K. Igarashi, N. Imamura, Y. Takahashi, Y. Tanaka, Y. Iwai, J. Antibiot., 1988, 41, 1769-1773.

540 H. Kumagai, H. Nishida, N. Imamura, H. Tomoda, S. Omura, J. Antibiot., 1990, 43, 1553-1558.

41 F. Trécourt, M. Mallet, O. Mongin, G. Quéguiner, J. Org. Chem., 1994, 59, 6173-6178.

42 M. Ohtawa, S. Ogihara, K. Sugiyama, K. Shiomi, Y. Harigaya, T. Nagamitsu, S. Omura, J. Antibiot., 2009, 62, 289-294.

43 J. Kohno, N. Hirano, K. Sugawara, M. Nishio, T. Hashiyama, N. Nakanishi, S. Komatsubara, Tetrahedron, 2001, 57, 1731-1735.

44 A. Fürstner, F. Feyen, H. Prinz, H. Waldmann, Angew. Chem. Int. Ed., 2003, 42, 5361-5364.

45 M. Tsuchinari, K. Shimanuki, F. Hiramatsu, T. Murayama, T. Koseki, Y. Shiono, Z. Naturforsch., B: Chem. Sci., 2007, 62, 1203-1207.

46 J. Zhan, A. M. Burns, M. X. Liu, S. H. Faeth, A. A. L. Gunatilaka, J. Nat. Prod., 2007, 70, 227$15 \quad 232$.

47 K. Ando, I. Matsuura, Y. Nawata, H. Endo, H. Sasaki, T. Okytomi, T. Saehi, G. Tamura, J. Antibiot., 1978, 31, 533-538.

48 Y. Nawata, I. Matsuura, K. Anso, Y. Iitaka, Acta Cryst., 1990, C46, 517-519.

49 D. R. Williams, P. D. Lowder, Y.-G. Gu, Tetrahedron Lett., 1997, 38, 327-330.

2050 J.-C. Kim, Y.-W. Lee, Appl. Environ. Microbiol., 1994, 60, 4380-4386.

51 J.-C. Kim, Y.-W. Lee, H. T. Tamura, T. Yoshizawa, Tetrahedron Lett., 1995, 36, 1047-1050.

52 L. Jayasinghe, H. K. Abbas, M. R. Jacob, W. H. M. W. Herath, N. P. D. Nanayakkara, J. Nat. Prod., 2006, 69, 439-442.

53 D. R. Williams, R. A. Turske, Org. Lett., 2000, 2, 3217-3220.

2554 T. Sassa, Agric. Biol. Chem., 1983, 47, 1417-1418.

55 P. S. White, J. A. Findlay, W. H. J. Tam, Can. J. Chem., 1978, 1904-1906.

56 N. N. Girotra, N. L. Wendler, Tetrahedron Lett., 1979, 50, 4793-4796.

57 J. Breinholt, S. Ludvigsen, B. R. Rassing, C. N. Rosendahl, J. Nat. Prod., 1997, 60, 33-35.

58 F. Koizumi, N. Fukumitsu, J. Zhao, R. Chanklan, T. Miyakawa, S. Kawahara, S. Iwamoto, M. Suzuki, S. Kakita, E. S. Rahayu, S. Hosokawa, K. Tatsuta, M. Ichimura, J. Antibiot., 2007, 60, $455-458$.

59 K. Tatsuta, T. Yamaguchi, Y. Tsuda, Y. Yamaguchi, N. Hattori, H. Nagai, S. Hosokawa, Tetrahedron Lett., 2007, 48, 4187-4190.

60 M. R. TePaske, J. B. Gloer, D. T. Wicklow, P. F. Dowd, Tetrahedron Lett. 1991, 32, 5687$35 \quad 5690$.

61 B. Snider, Q. Lu, J. Org. Chem., 1996, 61, 2839-2844.

62 C. Zhang, L. Jin, B. Mondie, S. S. Mitchell, A. L. Castelhano, W. Cai, N. Bergenhem, Bioorg. Med. Chem. Lett., 2003, 13, 1433-1435.

63 B. B. Snider, R. B. Smith, Synth. Comm., 2001, 31, 2667-2679.

4064 K. D. McBrien, Q. Gao, S. Huang, S. E. Klohr, R. R. Wang, D. M. Pirnik, K. M. Neddermann, I. Bursuker, K. F. Kadow, J. E. Leet, J. Nat. Prod., 1996, 59, 1151-1153.

65 H. V. K. Wangun, C. Hertweck, Org. Biomol. Chem., 2007, 5, 1702-1705.

66 R. Hosoya, T. Yugami, S.Yoshida, T. Yaguchi, K. Komuro, T. Sasaki, Japanese Patent 07,267,962-A; Chem. Abstr., 1996, 124, 143744k.

4567 Y. Fujita, H. Oguri, H. Oikawa, J. Antibiot., 2005, 58, 425-427.

68 Y. Fujita, H. Oguri, H. Oikawa, Tetrahedron Lett., 2005, 46, 5885-5888.

69 E. D. de Silva, A.-S. Geiermann, M. I. Mitova, P. Kuegler, J. W. Blunt, A. L. J. Cole, M. H. G. Munro, J. Nat. Prod., 2009, 72, 477-479.

70 M. M. Wagenaar, D. M. Gibson, J. Clardy, Org. Lett. , 2002, 4, 671-673.

5071 Y. Teshima, K. Shin-ya, A. Shimazu, K. Furihata, H. S. Chul, K. Furihata, Y. Hayakawa, K. Nagai, H. Seto, J. Antibiot., 1991, 44, 685-687.

72 A. Jegorov, V. Matha, M. Husak, B. Kratochvil, J. Stuchilik, P. Sedmera, V. Havlicek, J. Chem. Soc., Dalton Trans. 1993, 1287-1293.

73 B. B. Snider, Q. Lu, J. Org. Chem, 1994, 59, 8065-8070.

${ }_{55} 74$ P. Cai, D. Smith, B. Cunningham, S. Brown-Shimer, B. Katz, C. Pearce, D. Venables, D. Houck, J. Nat. Prod., 1999, 62, 397-399.

75 M. Isaka, M. Tanticharoen, J. Org. Chem., 2001, 66, 4803-4808.

76 I. L. Jones, F. K. Moore, C. L. L. Chai, Org. Lett., 2009, 11, 5526-5529. 
77 C. C. Hall, J. D. Watkins, N. H. Georgopapadakou, Antimicrob. Agents Chemother., 1989, 33, 322-325.

78 R. E. Dolle, K. C. Nicolaou, J. Am. Chem. Soc., 1985, 107, 1691-1694.

79 R. E. Dolle, K. C. Nicolaou, J. Am. Chem. Soc., 1985, 107, 1695-1698.

580 T. Weber, K. J. Laiple, E. K. Pross, A. Textor, S. Grond, K. Welzel, S. Pelzer, A. Vente, W. Wohlleben, Chem. Biol., 2008, 15, 175-188.

81 T. Shioiri, K. Ninomiya, S. Yamada, J. Am. Chem. Soc., 1972, 94, 6203-6205.

82 J. Weinstock, J. Org. Chem., 1961, 26, 3511.

83 E. Vedejs, S. Larsen, Org. Synth., 1987, 64, 127-137.

1084 D. P. Curran, Angew. Chem. Int. Ed. Engl., 1998, 37, 1175-1196.

85 E. Nicolas, K.C. Russell, V. J. Hruby, J. Org. Chem., 1993, 58, 766-770.

86 L. K. Blasdel, A. G. Myers, Org. Lett., 2005, 7, 4281-4283.

87 C. J. Cowden, I. Paterson, Org. React., 1997, 51, 1-200.

88 Y. Ito, T. Hirao, T. Seagusa, J. Org. Chem., 1978, 43, 1011-1013.

1589 D. R. Williams, P. D. Lowder, Y.-G. Gu, Tetrahedron Lett., 2000, 41, 9397-9401.

90 H. B. Henbest, R. A. L. Wilson, J. Chem. Soc., 1957, $1958-1965$.

91 S. Müller, B. Liepold, G. J. Roth, H. J. Bestmann, Synlett, 1996, 521-522.

92 P. Wipf, H. Jahn, Tetrahedron, 1996, 52, 12853-12910.

93 L. N. Mander, S. P. Sethi, Tetrahedron Lett., 1983, 24, 5425-5428.

2094 G. E. Keck, S. F. McHardy, T. T.Wager, Tetrahedron Lett., 1995, 36, 7419-7422.

95 D. B. Dess, J. C. Martin, J. Am. Chem. Soc., 1991, 113, 7277-7287.

96 K. Takai, K. Nitta, K. Utimoto, J. Am. Chem. Soc., 1986, 108, 7408-7410.

97 J. K. Stille, Angew. Chem. Int. Ed. Engl., 1986, 25, 508-524.

98 M. Mallet, G. Quéguiner, Tetrahedron, 1982, 38, 3035-3042.

2599 K. Green, J. Org. Chem., 1991, 56, 4325-4326.

100 K. Mori, S. Kuwahara, Tetrahedron, 1986, 42, 5545-5550.

101 M. Arisawa, C. Miyagawa, M. Yamaguchi, Synthesis, 2002, 138-145.

102 S. C. Dolan, J. MacMillan, J. Chem. Soc., Chem. Comm., 1985, 1588-1589.

103 S. A. Matlin, P. G. Sammes, J. Chem. Soc., Chem. Comm., 1972, 1222-1223.

30104 S. A. Matlin, P. G. Sammes, R. M. Upton, J. Chem. Soc., Perkins Trans. I., 1979, 10, $2481-$ 2487.

105 L. F. Tietze, S. Brand, T. Brumby, J. Fennen, Angew. Chem. Int. Ed. Engl., 1990, 29, 665-667.

106 J. Buck, J. P. Madeley, G. Pattenden, J. Chem. Soc., Perkins Trans. I., 1992, 67-77.

107 B. B. Snider, R. B. Smith, Synth. Comm., 2001, 31, 2667-2679.

35108 B. M. Trost, D. L. Van Vranken, Chem. Rev. , 1996, 96, 395-422.

109 P. R. Blakemore, W. J. Cole, P. Kocienski, A. Morley, Synlett, 1998, 26-28.

110 N. R. Irlapati, J. E. Baldwin, R. M. Adlington, G. J. Pritchard, A. R. Cowley, Tetrahedron, 2006, 62, 4603-4614.

111 M. J. Ackland, J. R. Hanson, P. B. Hitchcock, A. H. Ratcliff, J. Chem. Soc., Perkins Trans. I., $40 \quad 1985,4,843-847$.

112 P. Boy, C. Combellas, S. Fielding, A. Thiebault, Tetrahedron Lett., 1991, 32, 6705-6708.

113 G. J. Kontoghiorghes, Inorg. Chim. Acta, 1987, 135, 145-150.

114 M. C. Moore, R. J. Cox, G. R. Duffin, D. O’Hagan, Tetrahedron, 1998, 54, 9195-9206.

115 R. J. Cox, D. O’Hagan, J. Chem. Soc. Perkin Trans. 1,1991, 2537- 2540.

45116 X. Ma, D. R. Gang, Nat. Prod. Rep., 2004, 21, 752 - 772.

117 A. E. Farah, A. A. Alousi, Life Sci., 1978, 22, 1139-1148.

118 P. Fossa, G. Menozzi, P. Dorigo, M. Floreani, L. Mosti, Bioorg. Med. Chem., 2003, 11, 47494759. 